\title{
Using Retrofit Nail Base Panels to Expand the Market for Wall Upgrades
}

M. Del Bianco and J. Wiehagen Partnership for Home Innovation

February 2016 


\section{NOTICE}

This report was prepared as an account of work sponsored by an agency of the United States government. Neither the United States government nor any agency thereof, nor any of their employees, subcontractors, or affiliated partners makes any warranty, express or implied, or assumes any legal liability or responsibility for the accuracy, completeness, or usefulness of any information, apparatus, product, or process disclosed, or represents that its use would not infringe privately owned rights. Reference herein to any specific commercial product, process, or service by trade name, trademark, manufacturer, or otherwise does not necessarily constitute or imply its endorsement, recommendation, or favoring by the United States government or any agency thereof. The views and opinions of authors expressed herein do not necessarily state or reflect those of the United States government or any agency thereof.

Available electronically at SciTech Connect http:/www.osti.gov/scitech

Available for a processing fee to U.S. Department of Energy and its contractors, in paper, from:

U.S. Department of Energy

Office of Scientific and Technical Information

P.O. Box 62

Oak Ridge, TN 37831-0062

OSTI http://www.osti.gov

Phone: 865.576.8401

Fax: 865.576.5728

Email: reports@osti.gov

Available for sale to the public, in paper, from:

U.S. Department of Commerce

National Technical Information Service

5301 Shawnee Road

Alexandria, VA 22312

NTIS http://www.ntis.gov

Phone: 800.553 .6847 or 703.605 .6000

Fax: 703.605.6900

Email: orders@ntis.gov 


\title{
Using Retrofit Nail Base Panels to Expand the Market for Wall Upgrades
}

\author{
Prepared for: \\ The National Renewable Energy Laboratory \\ On behalf of the U.S. Department of Energy's Building America Program \\ Office of Energy Efficiency and Renewable Energy \\ 15013 Denver West Parkway \\ Golden, CO 80401 \\ NREL Contract No. DE-AC36-08GO28308 \\ Prepared by: \\ M. Del Bianco and J. Wiehagen \\ Home Innovation Research Labs \\ Partnership for Home Innovation \\ 400 Prince George’s Boulevard \\ Upper Marlboro, MD 207744 \\ NREL Technical Monitor: Stacey Rothgeb \\ Prepared under Subcontract No. KNDJ-0-40335-05
}

February 2016 
The work presented in this report does not represent performance of any product relative to regulated minimum efficiency requirements.

The laboratory and/or field sites used for this work are not certified rating test facilities. The conditions and methods under which products were characterized for this work differ from standard rating conditions, as described.

Because the methods and conditions differ, the reported results are not comparable to rated product performance and should only be used to estimate performance under the measured conditions. 


\section{Contents}

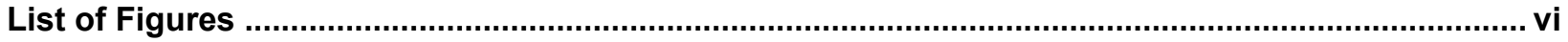

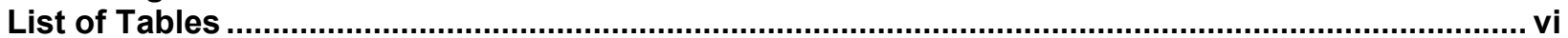

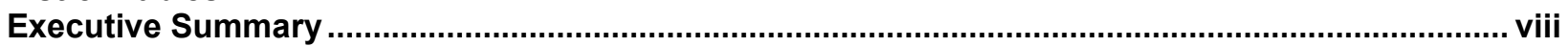

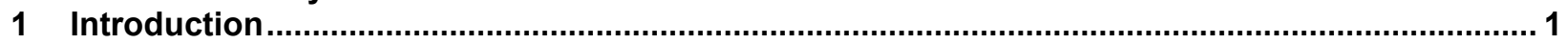

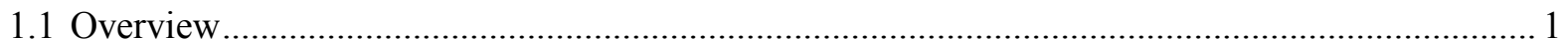

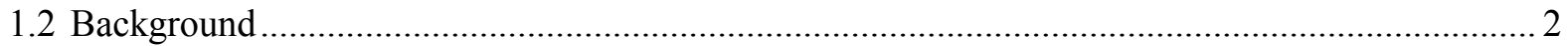

1.3 Modeling Method Used To Assess Conditions and Gauge Improvement .................................... 5

1.4 Goals 9

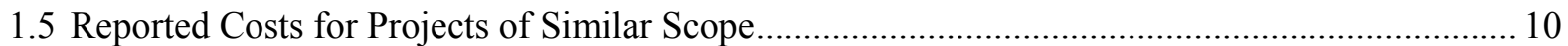

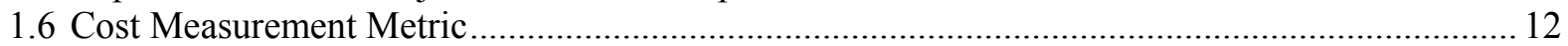

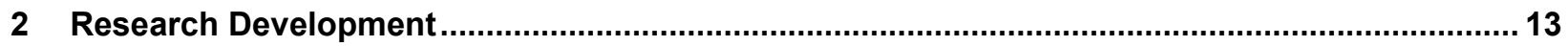

2.1 Scope 13

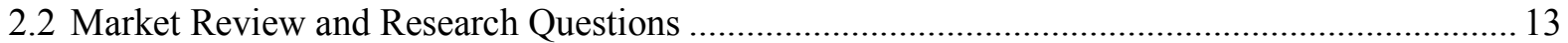

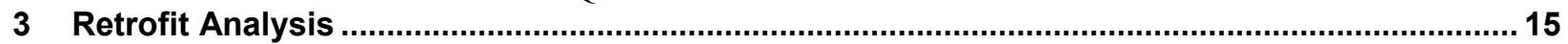

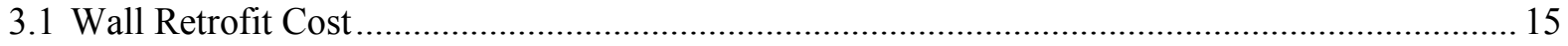

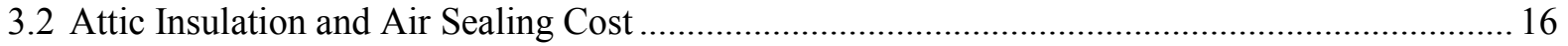

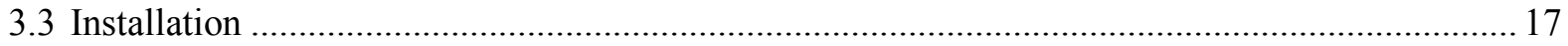

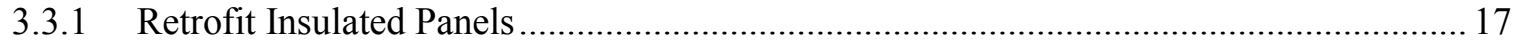

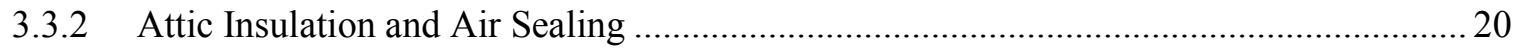

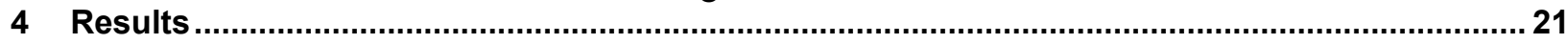

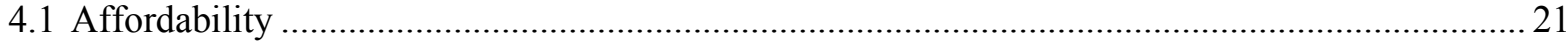

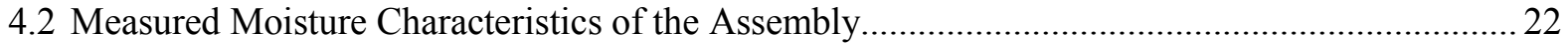

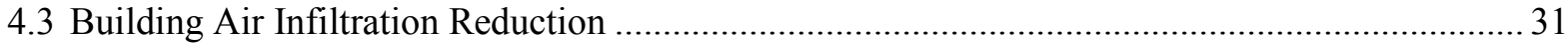

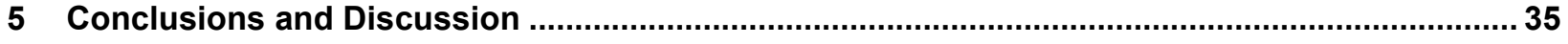

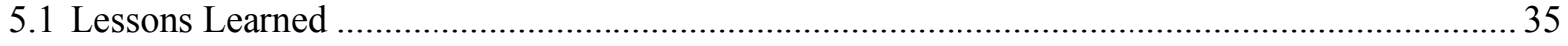

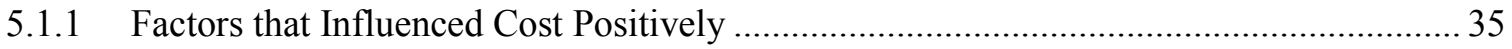

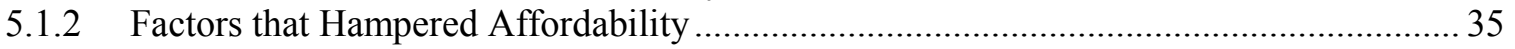

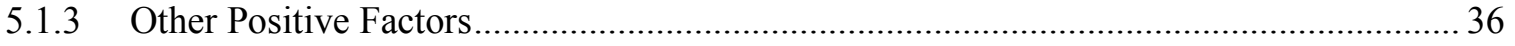

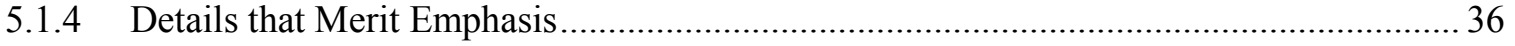

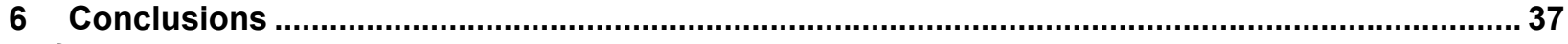

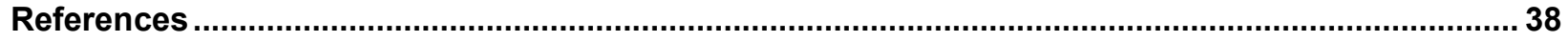

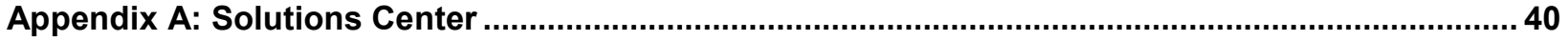

Appendix B: Indoor Conditions: Temperature and Relative Humidity .............................................47

Appendix C: Indoor Conditions: Daily Temperature Fluctuation................................................ 50 


\section{List of Figures}

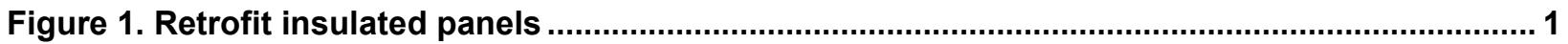

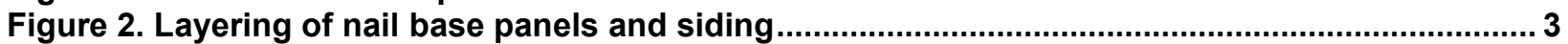

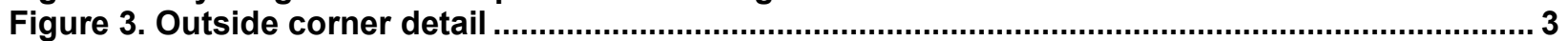

Figure 4. Foundation ledger for starting nail base panel installation ............................................ 4

Figure 5. SIP screw and piece of 6-in. graphite-enhanced EPS nail base panel ................................ 5

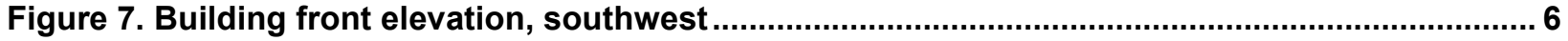

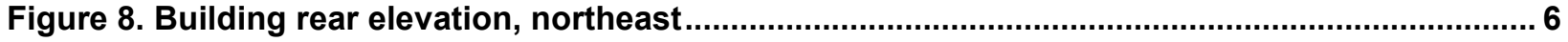

Figure 9. Rear patio doors and stairs at siding removal phase .................................................... 18

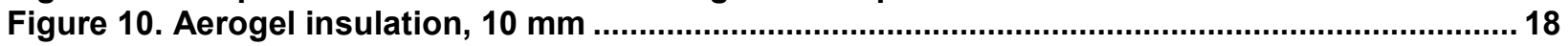

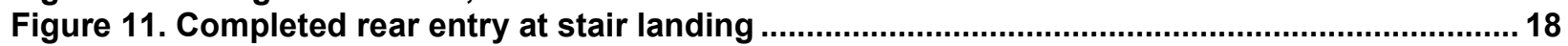

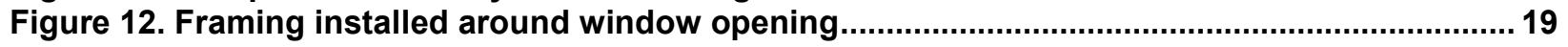

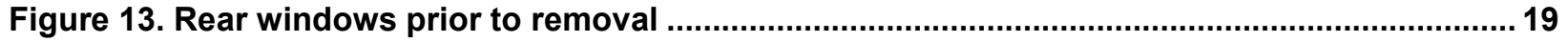

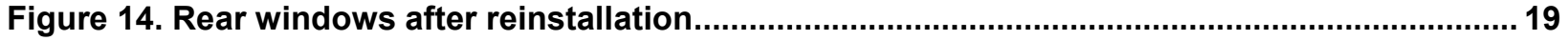

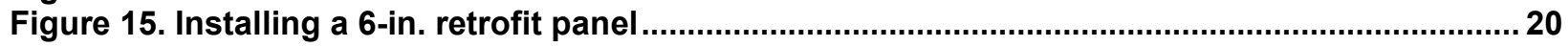

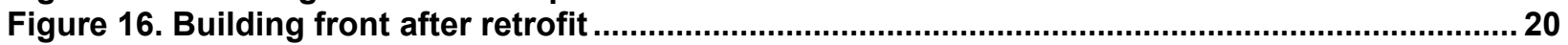

Figure 17. Comparison of costs for retrofit panels and costs associated with re-siding ................ 21

Figure 18. OSB moisture content-right section of building, units 150 basement, 150A, and 150B24

Figure 19. OSB moisture content-center section of building, units 152 basement, 152A, 152B, and

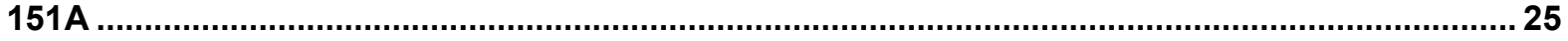

Figure 20. OSB moisture content-left section of building, units 153 basement, 153A, and 153B . 26

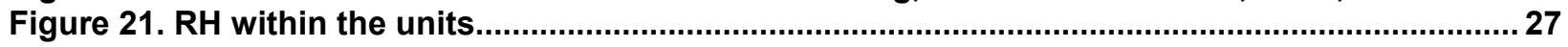

Figure 22. Condensation potential right section of building ........................................................ 28

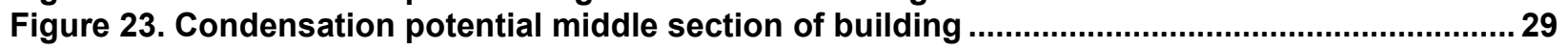

Figure 24. Condensation potential left section of building ............................................................... 29

Figure 25. Abandoned basement receptacle at CMU wall ................................................................. 31

Figure A-1. Typical retrofit panel installation starting from bottom of building ................................ 40

Figure A-2. Do start the retrofit panel layout at an outside corner of the building .......................... 43

Figure A-3. Do not apply spray foam to panel edges as sealant in freezing weather conditions .... 43

Unless otherwise noted, all figures were created by Home Innovation Research Labs. The Guide in Appendix B was created by PHI and the Structural Insulated Panel Association.

\section{List of Tables}

Table 1. BEopt Simulated Heat and Hot Water Use .................................................................... 8

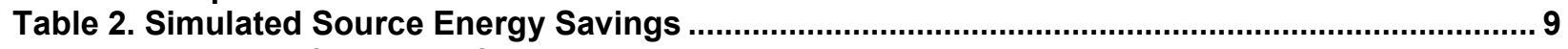

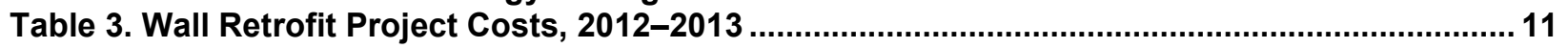

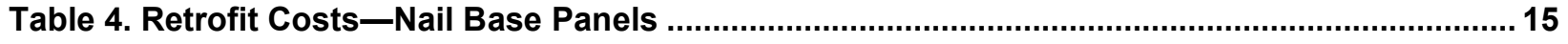

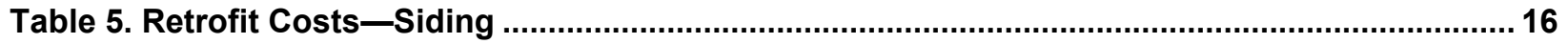

Table 6. Retrofit Costs_Attic Insulation, Air Sealing, and Ventilation ............................................. 17

Table 7. Locations and Identifications of Sensors Installed in the Building ................................. 22

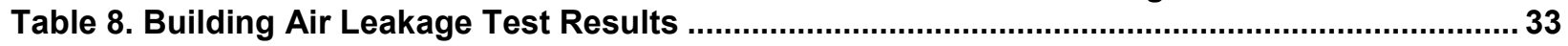

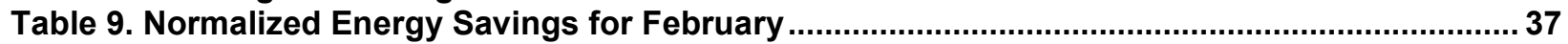

Table A-1. EPS Retrofit Insulated Panel R-Values ..................................................................... 41

Table A-2. Cost of 4-in. and 6-in. Retrofit Panel Installation per Shell Square Foot .......................... 42

Table A-3. Cost of Re-Siding per Square Foot of Installed Surface .............................................. 42

Unless otherwise noted, all tables were created by Home Innovation Research Labs. 


\section{Definitions}

ACH50 Air changes per hour depressurized to 50 Pascals

BEopt $^{\mathrm{TM}}$

CMU

DER

EPS

$\mathrm{ft}^{2}$

HDD

NYSERDA

OSB

PHI

$\mathrm{RH}$

R-value

SIP (a measure of a building's air tightness)

Building Energy Optimization E+ Version 2.0

Concrete masonry unit

Deep energy retrofit

Expanded polystyrene (rigid foam insulation)

Square Foot, Square Feet

Heating degree day

New York State Energy Research and Development Authority

Oriented strand board

Partnership for Home Innovation

Relative humidity

Capacity of insulation to resist heat transfer

Structural insulated panel 


\section{Executive Summary}

This project evaluated the effectiveness and affordability of integrating retrofit insulated panels into a re-siding project. The U.S. Department of Energy Building America research team Partnership for Home Innovation (PHI) worked with the New York State Energy Research and Development Authority, the Albany Housing Authority, and the New York State Weatherization Assistance Program (administered by the Albany Community Action Partnership) to demonstrate an energy retrofit and siding upgrade on a two-story, seven-unit, multifamily building in Albany, New York (Climate Zone 5). The project focused on three performance goals:

- Doubling the wall thermal resistance (from approximately R-13 to a weighted average of R-27)

- Reducing building air leakage

- Completing the retrofit within a budget in which the added cost of integrating the retrofit insulated panels is equal to the cost of the standard re-siding effort (i.e., the total cost of the energy-efficient re-siding scope of work is not more than twice the cost of the standard re-siding scope of work).

To promote the case for affordable exterior wall insulation and air-sealing retrofits and support practical paths to deliver wall energy upgrades to building owners within the context of the skill set typical to the home improvement industry, this report establishes a consistent metric for reporting remodeling costs for high-R-value walls. The proposed cost metric is formulated specifically around and in support of the remodeling activity as follows:

1. The cost of the recladding is excluded because that renovation activity stands on its own merits in the minds of consumers (see Section 2.2).

2. The cost is reported as the incremental cost for the energy-efficiency measures per installed square foot of the retrofitted wall or ceiling area rather than conditioned floor area.

3. The retrofit cost of the energy feature is compared to the cost of the typical re-siding effort as a ratio that can be used to directly evaluate the affordability of the overall project.

By these metrics, the costs of the energy retrofit are presented as incremental to the costs of the basic remodel activity; in this case new cladding.

Final results of the cost analysis show that the cost to install the retrofit insulated panels was $\$ 7 / \mathrm{ft}^{2}$, which is slightly higher than the target of the standard re-siding cost of $\$ 6.10 / \mathrm{ft}^{2}$. This corresponds to a ratio of the cost of the energy-efficiency measure to the cost of a traditional façade improvement of 1.15. This cost level of the energy-efficiency upgrade supports Building America goals of providing a reliable and economical energy-efficiency measure option for existing buildings and a pathway for market expansion by trades contractors and remodelers.

In addition to the exterior insulation upgrade, the energy-efficiency retrofit included adding attic insulation and installing air-sealing measures in accordance with standard weatherization 
protocols. Based on limited monitoring of the building's energy use after the retrofit, the total heating savings were $21 \%$ (heating degree day normalized), which is lower than the expected $30 \%$. The difference was attributed to higher average indoor temperatures after the retrofit and observed opening of windows by the occupants to moderate indoor temperatures because the heating controls in each unit were inaccessible.

Moisture performance investigations indicate that the retrofit insulated panels in these units lead to lower moisture levels than the oriented strand board (OSB) sheathing and less OSB moisture content variation throughout the year. Further monitoring to confirm these results is recommended.

Lessons learned from the project strongly indicate that the retrofit insulated panel technology can be implemented using common installation practices and with minimal training. These lessons also demonstrate that advanced training methods would enhance the quality and efficiency of the installation. Other lessons learned include limitations on the use of standard air-sealing materials during cold-weather installations and the need to develop better installation guidance for tradespeople who are working with the level of tolerances in the structure.

This technology demonstration focused on increasing the wall insulation in existing buildings and showed that exterior retrofit insulated panels provide a viable and reasonable option for the siding trades to increase market opportunities and achieve synergistic benefits for aesthetic upgrades to a building's exterior. 


\section{Introduction}

\subsection{Overview}

The U.S. Department of Energy Building America research team Partnership for Home Innovation (PHI) undertook an investigation into the cost and constructability of a single product, a retrofit insulated panel, also called a nail base, to support overall research goals to sustain the increased thermal performance of walls in existing buildings and as the first step in a deep energy retrofit (DER) project sponsored by the New York State Energy Research and Development Authority (NYSERDA) (Figure 1). The panel component is a scalable wall insulation product formed by structural insulated panel (SIP) manufacturers that consists of an expanded polystyrene (EPS) core with one face of 7/16-in. oriented strand board (OSB); these panels are available in customizable thicknesses of even increments from 4 to 12 in.

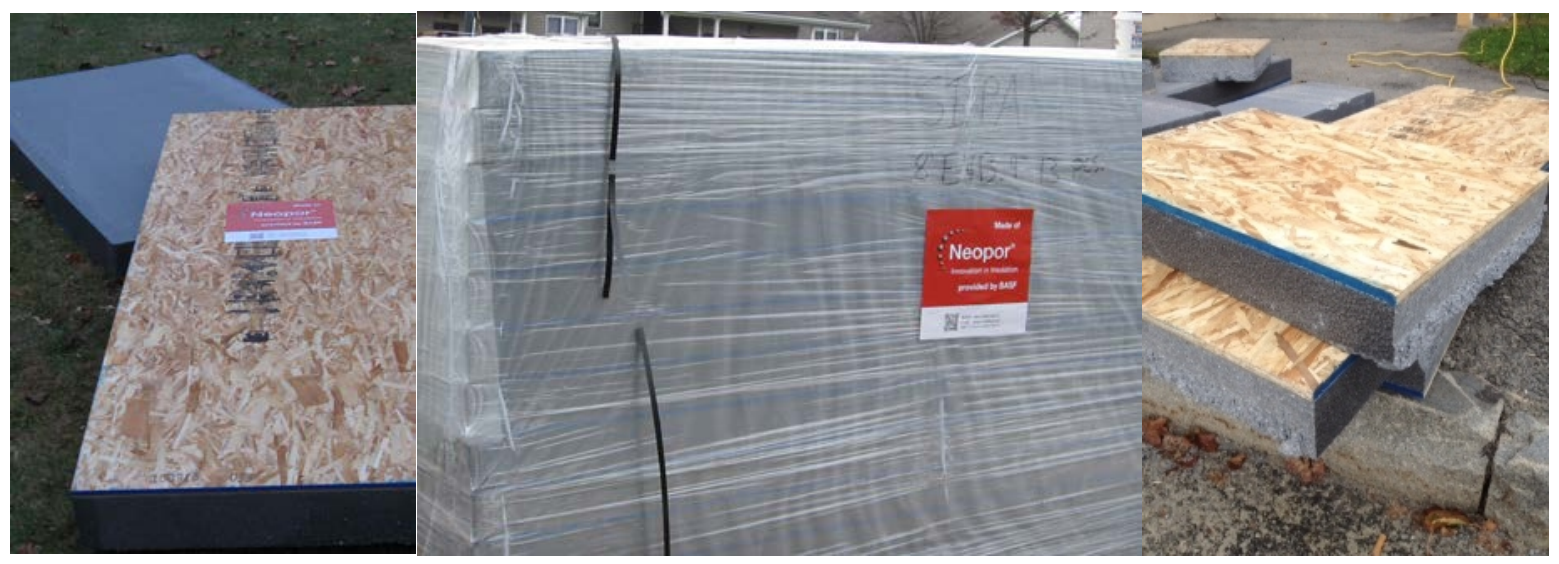

Figure 1. Retrofit insulated panels

This project evaluated the effectiveness and affordability of integrating retrofit insulated panels into a re-siding project. With support from the Building America Program, PHI teamed with NYSERDA, the Albany Housing Authority, and the New York State Weatherization Assistance Program (administered by the Albany Community Action Partnership) to demonstrate an energy retrofit and siding upgrade on a two-story, seven-unit, multifamily building in Albany, New York (Climate Zone 5).

The project focused on three performance goals:

- Doubling the existing wall thermal resistance (from approximately R-13 to a weighted average of R-27)

- Reducing building air leakage

- Completing the retrofit within a budget in which the added cost of integrating the retrofit insulated panels is equal to the cost of the standard re-siding effort (i.e., the total cost of the energy-efficient re-siding scope of work is not more than twice the cost of the standard re-siding scope of work).

This demonstration project was undertaken with the aim of simplifying the details of a highR-value wall assembly for contractors. Installation cost-control methods were identified, 
standardized, and detailed in a guide (SIPA 2014) so that the option of adding exterior insulation by this method could be quantified with greater certainty at the outset of a re-siding job.

\subsection{Background}

The addition of significant exterior insulation at the same time the siding replacement is planned saves the labor of removing and reinstalling the cladding to accommodate the insulation later. And because the walls contain the largest surface area of a typical residential structure, they provide the building's primary planes for effective additional insulation and air sealing. In the case of the two-story building with a rear walkout basement that served as this demonstration site, the exterior walls represent $56 \%$ of the building surfaces that abut unconditioned areas. The second-floor ceiling and basement floor each represent $22 \%$ of the exterior and ground contact surfaces.

The building science community has benefited from more than 40 years of experimentation in methods and materials for tightly insulated, light-frame structures. Recent case studies about 4in.-thick foam walls were presented by NYSERDA and Building America teams, some of which are covered in Section 3.1. These cases continue to rely on two layers of rigid foam plus furring for a siding fastening surface or added exterior studs and spray foam to add thermal resistance as opposed to the single component introduced in this demonstration project.

Like some traditional methods, the exterior location of new insulation in retrofit insulated panel construction causes minimal interruption to the occupants' lifestyle and adds R-value outside the structural frame. Improving the air, water, and thermal seal of a building with new materials from the outside is a streamlined method of bypassing the tedium involved with individually locating and sealing the myriad of openings in the walls of older buildings. Risk is mitigated by the years of in-service performance of similarly constructed buildings and the known-and thus avoidable - idiosyncrasies of the construction method; e.g., moisture and pest intrusion and the repetition of installing numerous components. However, the application of several layers of rigid insulation, tape, furring, and siding introduces its own tedium in the number of passes around the building that are required to complete this type of assembly. The retrofit insulated panel method provides a single insulation component installed at the building's exterior that incorporates an OSB nailing face for siding application and wall air sealing.

Nail base panels comprise a rigid foam core and one face of 7/16-in. OSB. Most often, the core of a nail base panel is EPS, which typically provides a thermal resistance of 3.8/in. The panels are also available with a graphite-enhanced EPS that can be identified by its distinctive gray color. (EPS is white.) The graphite-enhanced EPS has an R-value of 4.5 in. (BASF 2014). This demonstration project employed BASF's Neopor, a graphite-enhanced, vapor-permeable EPS that allows the thick wall assemblies to have a higher R-value and the ability to dry to the outside - a desirable feature in a cold climate. ${ }^{1}$

To eliminate the time that is consumed figuring out details that should be standard or sourcing fasteners and other components that could be stock, the Structural Insulated Panels Association (SIPA 2015) developed a comprehensive guide concurrent with the planning and implementation

\footnotetext{
${ }^{1}$ The manufacturer reports that the permeance of a 4-in. panel is 0.72 and 0.51 for a 6 -in. panel and classifies both as Class II vapor barriers (www.neopor.basf.us/performance).
} 
of the demonstration project covered in this technical report. The guide is intended to provide a single source for builders/trades to design, plan, and install wall/roof upgraded insulation using retrofit insulated panels.

Some excerpts from the guide include Figure 2, which indicates the sequence of attachment of retrofit panels, weather barrier, and cladding to the structure. Panels are sealed to each other with panel adhesive (mastic) or spray polyurethane foam. Panel edges at plane transitions, such as outside corners, are sealed with dimensional lumber and spray polyurethane foam (Figure 3). Retrofit panel layout typically begins at an inside corner because that is the hardest place to air seal. Panels at the bottom of the wall are placed on a ledger inset into the panel's foam that also acts as an insect guard (Figure 4).
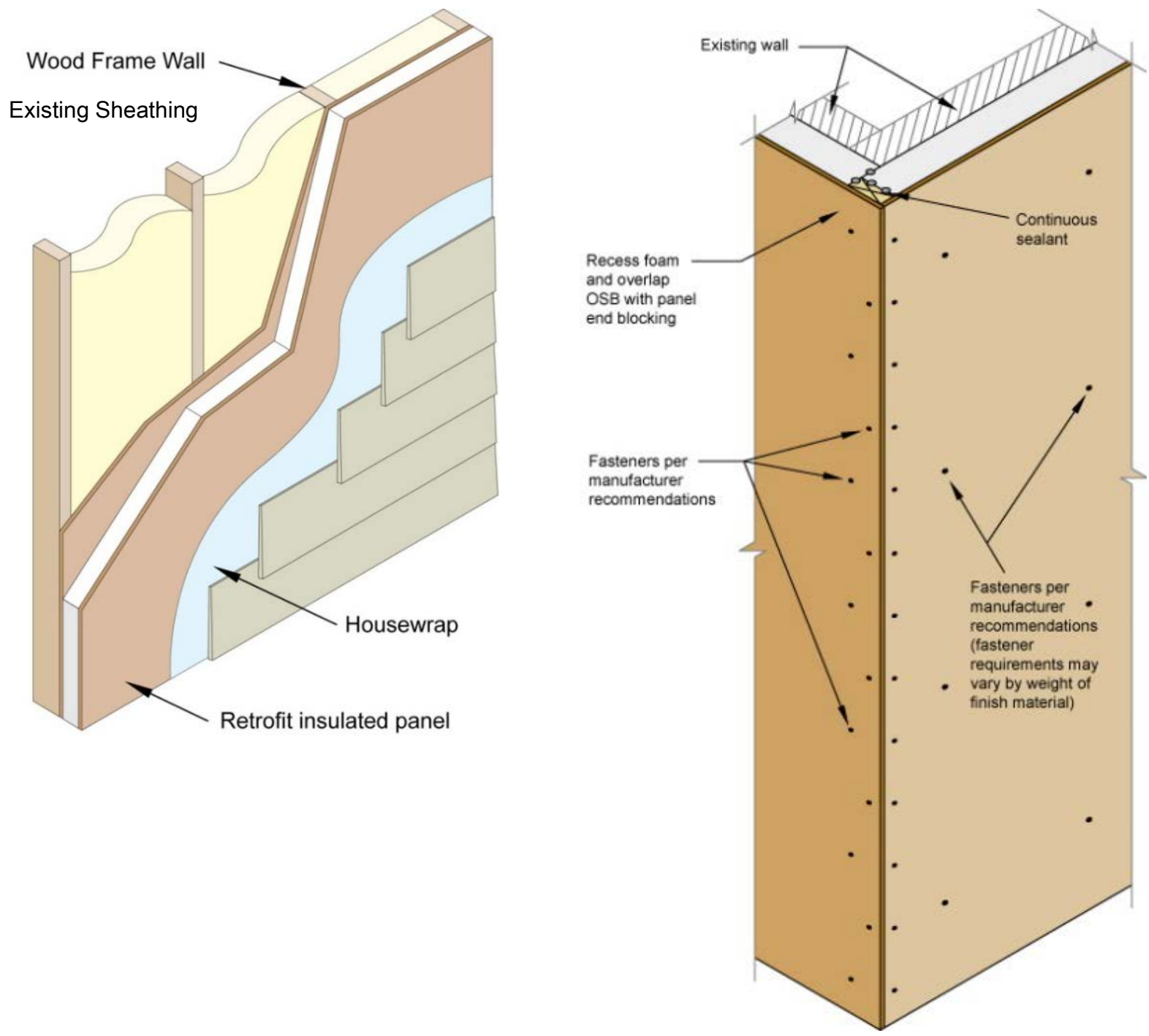

Figure 2. Layering of nail base panels and siding

Figure 3. Outside corner detail 


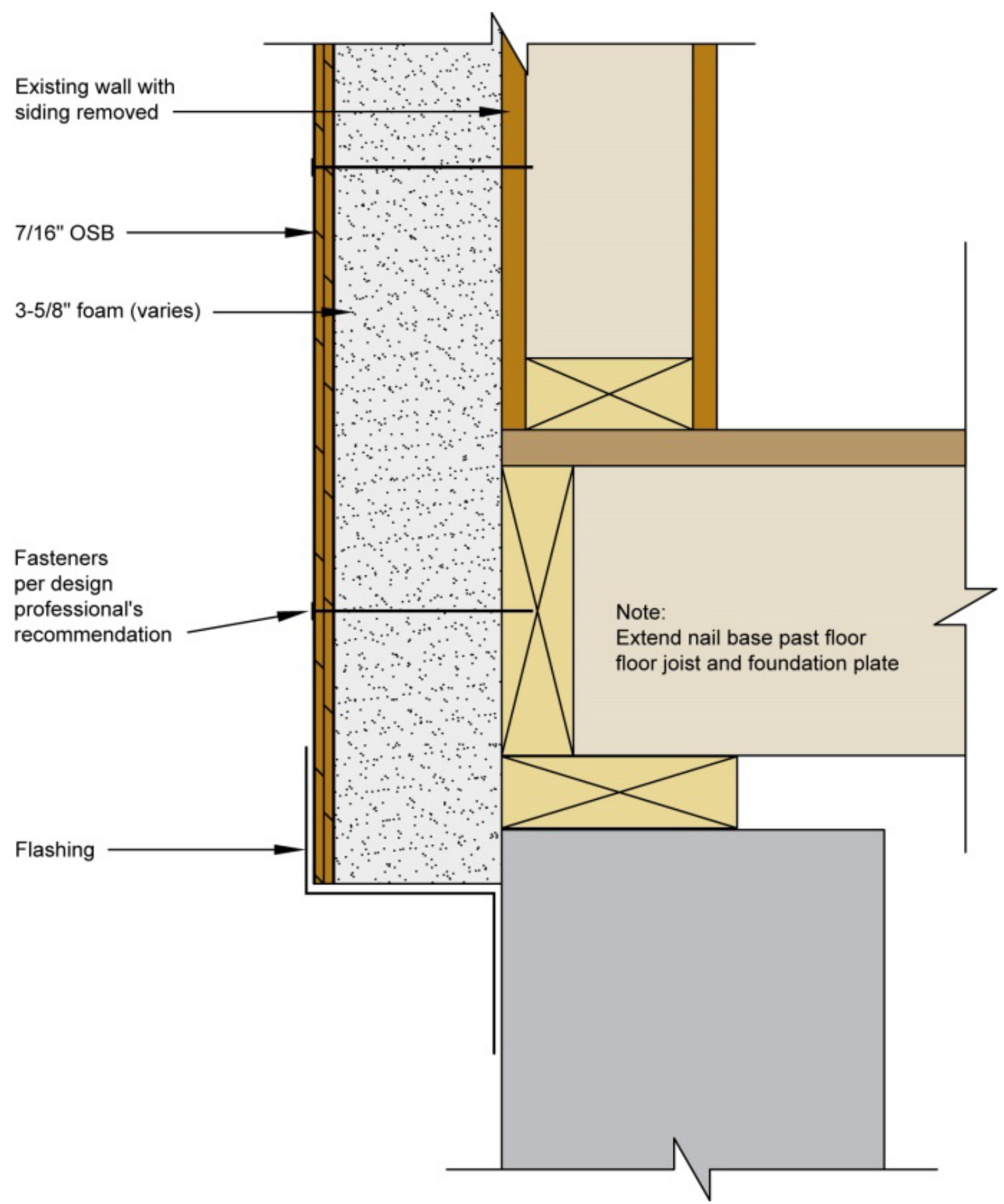

Figure 4. Foundation ledger for starting nail base panel installation

Retrofit insulated panels are secured to the framing with long fasteners called SIP screws (Figure 5). This product was developed specifically for the remodeling market by SIP manufacturers. 


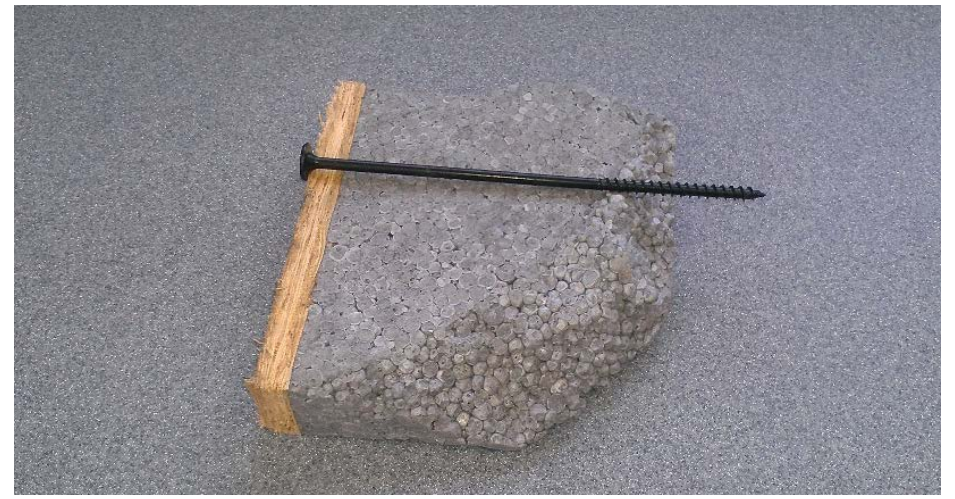

Figure 5. SIP screw and piece of 6-in. graphite-enhanced EPS nail base panel

The fastening schedule for attaching nail base panels to the wall frame is based on the weight of the nail base panel plus the weight of the cladding that will subsequently be attached to the OSB face of the nail base panels. Because the fasteners must penetrate the wall framing, the fastener schedule must be also coordinated with the spacing of the studs. Panels that support vinyl and fiber-cement siding have a fastening schedule of 16-24 in. when the studs that support the panels and cladding are spaced at 16 in. on center.

\subsection{Modeling Method Used To Assess Conditions and Gauge Improvement}

The demonstration project was a two-story building with a 4-ft, in-ground basement in the front and a daylight basement in the rear in Climate Zone 5, Albany, New York. The seven-unit building consists of single-story units of two, three, or five bedrooms. Each has a kitchen, bath, and living area. Additional units, which had been located in the basements, were abandoned in a 1998 rehabilitation. The building is laid out as three row house/unit combinations separated by concrete masonry unit (CMU) walls. Two units stacked on each end and a single unit and two above comprise the middle section of the building. Figure 6 is a schematic of the layout of the seven units and the locations of the CMU walls. Figure 7 and Figure 8 are photographs of the building.

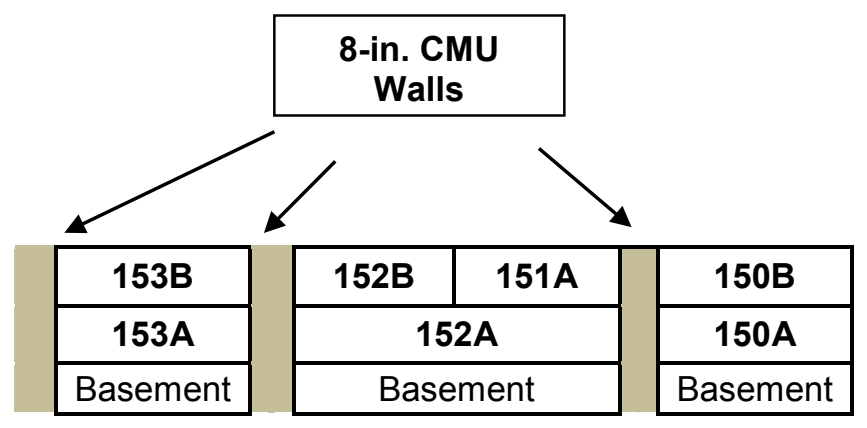

Figure 6. Unit layout and identification 


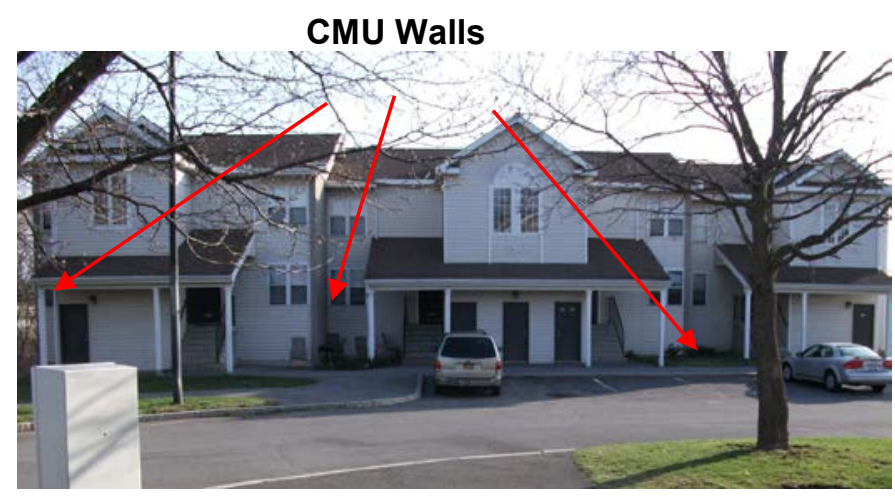

Figure 7. Building front elevation, southwest

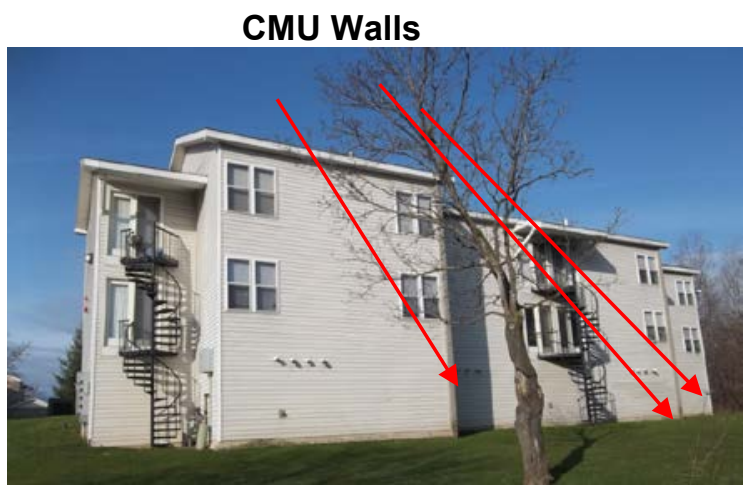

Figure 8. Building rear elevation, northeast

The building's unfinished basement houses the boilers and water heaters that are metered to the building separately from the apartments. Heat is provided by two 175-MBtu natural gas boilers that supply heated water to piping that is laid out in a continuous loop configuration. The heated water is circulated by a 1-horsepower pump that runs continuously during the heating season, which the State of New York defines as October through May for rental housing. ${ }^{2}$ Hot water is provided by two 40-gallon natural gas tank units that are ganged together in the locked basements to supply two to three units in the row house.

A site inspection of the building and each unit was performed in April 2013. Blower door testing was performed on each unit individually; each unit was then tested simultaneously with an adjacent unit on the apartments located between the CMU firewalls. Tests were designed to differentiate between air leakage to adjacent (conditioned) units above and below the subject unit and air leakage to the outside. The overall leakage rate that was measured, approximately 8.3 ACH50, is lower than average for a building of this vintage (Antretter et al. 2007). See Appendix $\mathrm{C}$ for blower door test results and preexisting conditions.

Each apartment in the building was simulated using Building Energy Optimization E+ Version 2.0 (BEopt $^{\mathrm{TM}}$ ) in accordance with one of the following: (1) as a one-story unit with superinsulated $^{3}$ crawlspace and flat super-insulated roof (midlevel units); (2) as a one-story unit with attic and super-insulated crawlspace floor (top units); or (3) as one-bedroom and bath slab units with a super-insulated roof (basement units). Nine BEopt simulation runs were aggregated (the same values were used for units 152B and 151A). Only heat and hot water loads were recorded for each unit, and only heat was recorded for the basements because these are unoccupied, unfinished, and locked from access by all but maintenance personnel. No running water is accessible from the basement. Table 1 shows the results of the computer simulations for each unit in therms and kilowatt hours. Simulated use was reconciled with actual use provided by National Grid, the delivery utility for natural gas and electricity. A post-simulation calculation of

\footnotetext{
${ }^{2}$ New York State law requires landlords to make heat available to tenants from Oct. 1 through May 31 within stated temperature delta constraints (www.nyc.gov/html/hpd/html/tenants/heat-and-hot-water.shtml).

${ }^{3}$ The term super-insulated is used to describe a modeling technique in which a maximum level of insulation as possible in the software is used for modeling purposes to reduce energy losses through that surface to the levels that are insignificant relative to other energy losses in the simulated building.
} 
the estimated electricity use of the 1-horsepower hydronic pump that operates continuously throughout the heating season was made and entered as a separate line item.

According to utility company statements, simulated natural gas use was $14 \%$ lower than the actual natural gas use. With the inclusion of a post-processing calculation for pump electricity use, simulated electricity use was $20 \%$ lower than actual for the year that ended Mar. 31, 2013. The difference between the simulation and the actual is thought to be partly attributable to tenant waste caused by windows that do not close, location of hydronic controls behind large pieces of furniture (which makes them inaccessible), and lack of thermostatic controls for the heating system. Higher heating set temperatures than those simulated have been observed in the units after the remote reporting sensors were installed. The temperature and relative humidity (RH) sensors were placed at the time of the initial building inspection in April 2013. Appendix B includes graphs of indoor conditions for several parts of two heating seasons. 
Table 1. BEopt Simulated Heat and Hot Water Use

\begin{tabular}{|c|c|c|c|c|c|c|c|c|c|c|c|c|}
\hline Energy Use & Unit & $\stackrel{\pi}{n}$ & $\stackrel{\infty}{n}$ & $\underset{\pi}{\pi}$ & $\stackrel{\infty}{\sim}$ & $\underset{n}{n}$ & $\underset{8}{\mathscr{8}}$ & $\stackrel{n}{\underline{1}}$ & 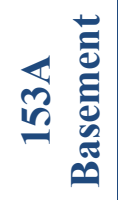 & 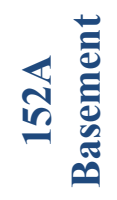 & 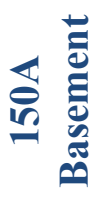 & Subtotal \\
\hline Heat & Therms/yr & 212 & 309 & 373 & 282 & 282 & 219 & 129 & 674 & 519 & 674 & 3,673 \\
\hline Hot Water & Therms/yr & 182 & 184 & 255 & 160 & 160 & 188 & 151 & 0 & 0 & 0 & 1,280 \\
\hline Miscellaneous Gas & Therms/yr & 6 & 6 & 8 & 6 & 6 & 6 & 7 & 6 & 6 & 5 & 62 \\
\hline Total & Therms/yr & 400 & 499 & 636 & 448 & 448 & 412 & 287 & 680 & 525 & 679 & 5,015 \\
\hline $\begin{array}{l}\text { Heating, Ventilating, and } \\
\text { Air-Conditioning Pump }\end{array}$ & $\mathrm{kWh} / \mathrm{yr}$ & 26 & 38 & 46 & 35 & 35 & 26 & 15 & 70 & 80 & 21 & 392 \\
\hline Heat & $\mathrm{kWh} / \mathrm{yr}$ & 44 & 70 & 44 & 50 & 50 & 44 & 21 & 76 & 82 & 44 & 525 \\
\hline $\begin{array}{c}\text { Calculated Additional } \\
\text { Pump Use }\end{array}$ & $\mathrm{kWh} / \mathrm{yr}$ & 392 & 566 & 685 & 523 & 523 & 392 & 218 & 1,046 & 1,252 & 305 & 5,902 \\
\hline Total & $\mathrm{kWh} / \mathrm{yr}$ & 462 & 674 & 775 & 608 & 608 & 462 & 254 & 1,192 & 1,414 & 370 & 6,819 \\
\hline
\end{tabular}


Doubling the wall R-value to R-25, doubling the ceiling R-value to R-49, and air sealing the building to $3 \mathrm{ACH} 50$ indicated a whole-building approach improvement of $29 \%$ in source energy savings and $38 \%$ when the equipment upgrade is completed (Table 2).

Table 2. Simulated Source Energy Savings

\begin{tabular}{c|c|c|c}
\hline Use Category & $\begin{array}{c}\text { Pre- } \\
\text { Retrofit }\end{array}$ & $\begin{array}{c}\text { Envelope } \\
\text { Post-Retrofit }\end{array}$ & $\begin{array}{c}\text { Envelope and } \\
\text { Equipment Post- } \\
\text { Retrofit }\end{array}$ \\
\cline { 2 - 4 } & \multicolumn{2}{|c}{ Source Energy Use (MBtu/yr) } \\
\hline Miscellaneous (Electricity) & 59.43 & 59.43 & 59.43 \\
Vent Fan (Electricity) & 15.50 & 19.14 & 19.14 \\
Large Appliances (Electricity) & 54.81 & 54.81 & 54.81 \\
Lights (Electricity) & 32.14 & 31.31 & 31.31 \\
Heating, Ventilating, and Air- & & & \\
Conditioning Fan/Pump & 3.37 & 1.70 & 1.7 \\
(Electricity) & 137.04 & 72.44 & 61.81 \\
Heating (Electricity) & 193.90 & 108.00 & 88.55 \\
Heating (Natural Gas) & 239.57 & 174.34 & 141.42 \\
Hot Water (Natural Gas) & 735.76 & 521.17 & 458.17 \\
Total & & $29.2 \%$ & $37.8 \%$ \\
\hline Percentage Source Energy Savings & & & \\
\hline
\end{tabular}

\subsection{Goals}

For existing homes, the goal of the Building America program is to research and demonstrate affordable and buildable methodologies to reduce energy use by $30 \%$ from pre-retrofit conditions (by 2015). To meet this goal, PHI conducted research into the use of a retrofit wall panel that comprises graphite-enhanced EPS with one OSB skin to advance market-ready energy-efficiency solutions in buildings.

For the 44\% of the nation's housing stock built before 1970 (Census Bureau 2011), tackling the replacement of failing or degrading exterior coverings presents the ideal opportunity to improve a home's comfort and energy efficiency along with its curb appeal. The challenge is to maximize the insulating value of the materials applied to the walls of these homes and minimize associated product and installation costs such that the incremental cost of the insulation and air sealing compares favorably to the cost of the siding, window, or door replacement. In this case study, a metric is proposed that relates the added cost of energy-efficient features to the cost of the standard retrofit activity. The targeted goal is to contain the added cost of wall insulation and airsealing improvements to about the same level as the cost of a standard siding installation.

This demonstration project sought to achieve the Building America energy goal by specifying a set of retrofit measures for the building envelope that coincided with a planned façade upgrade. These measures were modeled to provide a minimum of $29 \%$ initial source energy savings to the building's metered energy use (supplying heat, hot water, and minimal safety lighting). Primary measures were wall exterior insulation, attic insulation, and air sealing provided by the wall panel installation and measures to be applied to the attic. The measures are expected to be followed by a three-year plan to improve the efficiency of the equipment that supplies heat and 
hot water. The results are expected to provide valuable information about the cost-effectiveness of retrofit measures using this panel product for building owners and trades nationwide.

The case study primarily focused on the two building meters for their ease of access for measurement:

- An electricity meter that services building exterior lighting and interior lighting in the basement, the 1-horsepower hydronic pump, and power venting of six water heaters and two boilers

- A natural gas meter that supplies the primary fuel to the water heaters and boilers.

Albany Housing Authority operates this housing and pays for these utilities within the U.S. Department of Housing and Urban Development Section 8 program guidelines. The outcome after comparing pre- and post-retrofit heating seasons will help direct the next course of action for this building and the 18 others in the neighborhood. That decision will hinge around whether to upgrade the equipment and maintain the central meters or to provide for individual heat and hot water and separate these meters so the tenants in each unit pay for their own utilities, including heat and hot water.

\subsection{Reported Costs for Projects of Similar Scope}

A northeastern utility, National Grid, NYSERDA, and Building America have all sponsored and reported on DER projects that highlight the addition of insulation of significant thermal resistance on foundations, above-grade walls, and roofs and ceilings. Results from a recent NYSERDA effort that focused on tightly sealed and insulated walls and cost containment are shown in Table 3 (Herk 2012a, 2012b, 2013). Metrics for these 2012 NYSERDA DER programs measured and reported the cost of these energy-efficiency measures by shell square footage of affected area (Table 3). Other projects that might be comparable were less forthcoming about the relationship between costs and the surface area actually covered.

These demonstration projects reported that the costs for adding wall insulation were $\$ 8.94$ $\$ 10.75 / \mathrm{ft}^{2}$ for above-grade wall for added thermal resistance values from R-18 to R-30. In two of the three cases the cost for the wall energy-efficiency measures was lower than the cost to re-side the house. Additional reported costs, such as windows, have been omitted for comparison, because some projects did not receive new windows. Siding costs reported do include window trim. 
Table 3. Wall Retrofit Project Costs, 2012-2013

\begin{tabular}{|c|c|c|c|}
\hline \multirow[b]{2}{*}{ Wall Insulation Method } & $\begin{array}{c}\text { DER \#1-One-Story } \\
2 \times 4 \text { Studs }\end{array}$ & DER \#2-One-Story & DER \#3-Two-Story \\
\hline & $\begin{array}{c}\text { With 3.5-in. Closed-Cell } \\
\text { Spray Polyurethane } \\
\text { Foam }\end{array}$ & $\begin{array}{l}\text { Two-Ply 2-in. } \\
\text { Rigid Foam }\end{array}$ & $\begin{array}{c}\text { 3-in. Extruded } \\
\text { Polystyrene and } \\
\text { R-15 Blown } \\
\end{array}$ \\
\hline Approximate Added R-Value & 18.6 & 20 & 30 \\
\hline Floor Area (Conditioned), $\mathbf{f t}^{2}$ & 2,276 & 1,804 & 2,688 \\
\hline Wall area (Above Grade), $\mathbf{f t}^{2}$ & 2,056 & 1,600 & 2,032 \\
\hline Wall Retrofit Cost (Above Grade) & $\$ 18,378$ & $\$ 15,978$ & $\$ 21,855$ \\
\hline Wall Retrofit Cost, $\$ / \mathbf{f t}^{2}$ & $\$ 8.94$ & $\$ 9.99$ & $\$ 10.75$ \\
\hline Siding Cost & $\$ 23,714$ & $\$ 20,334$ & $\$ 18,026$ \\
\hline Siding Cost, $\$ \mathbf{S} / \mathbf{f t}^{2}$ & $\$ 11.53$ & $\$ 12.71$ & $\$ 8.87$ \\
\hline Total Wall Cost, $\$ / \mathbf{f t}^{2}$ & $\$ 20.47$ & $\$ 22.70$ & $\$ 19.62$ \\
\hline Floor-Wall Ratio & 1.11:1.00 & 1.13:1.00 & 1.32:1.00 \\
\hline
\end{tabular}

Note: Bold numbers are compiled from reported statistics. 


\subsection{Cost Measurement Metric}

The wall square-foot metric that was introduced in Table 3 provides a determinate measurement of expected cost because wall square footage is usually smaller than conditioned floor square footage, particularly with multistoried buildings. Yet, when a siding contractor is quoting a job cost, he or she is speaking about the square footage of the surface to be covered, not the conditioned floor area.

The National Grid DER program refers to costs and allowable incentives to offset these as "square foot of treated area." ${ }^{4}$ To measure cost accurately this report will refer to cost as relative to square foot of treated area, or the surface that will be covered with material.

\footnotetext{
${ }^{4}$ The National Grid website indicates that incentives are designed as "roof only," "wall only," and "basement only" per treated square foot so they align with re-roofing, re-siding, and basement fit-out maintenance projects typically contracted by homeowners (www.masssave.com/residential/offers/der-national-grid).
} 


\section{Research Development}

\subsection{Scope}

The primary improvements to the building for this energy retrofit were high wall and ceiling thermal resistance and an envelope air seal. Because the building owner preferred to retain the appearance of the several exterior split-face masonry walls, some wall sections (the rear and east side walls) that currently have vinyl siding as cladding were planned with more insulation than other surfaces so the building's weighted average opaque wall R-value after the retrofit would reach or exceed R-25, and the split-face CMU walls remained without any changes.

The project focused primarily on affordability, reductions in air infiltration and energy use, and durability. Providing contractor training and installation experience was a secondary goal.

\subsection{Market Review and Research Questions}

Although DERs have been accepted for their performance results, claims of true technical success should include some degree of cost containment. Recognizing and enumerating the cost trade-offs that consumers make in home improvement decisions and the offer of a solution at a lower price point, or a price that is a factor of the known cost of the siding replacement should facilitate wider presentation and adoption of shell energy retrofits secondary to replacement projects that enhance curb appeal.

A study from the Joint Center for Housing Studies of Harvard University (JCHS 2013) about the U.S. housing stock reports two categories of owner investment in housing: improvement and maintenance and includes (siding) replacement as an improvement. This increases the value of the housing stock versus maintenance, which merely preserves current market value. Remodeling Magazine statistics support the Housing Studies of Harvard University added value from improvement concept; it reports that homeowners nationwide receive a $70 \%$ return on the $\$ 11,800$ average cost of a re-siding project (Alfano 2013). A 2011 survey of 2,000 German oneand two-family households revealed that building appearance was the initial driver for thermal retrofit decisions for those not planning to add insulation. The findings suggest that policy tools that link aesthetics and energy efficiency could be most effective in motivating homeowner investment in energy efficiency in tandem with planned home improvements (Novikova et al. 2011). In the study homeowners who had completed aesthetic and thermal retrofits listed thermal comfort and poor building performance as larger motivators than appearance once the job was completed, whereas the opposite was true for homeowners in the planning stage of an aesthetic remodel who did not want to make the investment in time and money to research the options, costs, and paybacks available with an energy retrofit and were generally satisfied with their homes at the time. In a similar twist on homeowners' statements of cause and effect, Diamond et al. (2010) reported that U.S. homeowners' pre-renovation decisions are motivated by emotions and aesthetics, whereas post-renovation explanations are economically justified. A lack of information that is understandable and consistently formatted is also blamed for the failure of U.S. homeowners to widely adopt energy-efficiency retrofits (McIlvaine et al. 2013).

These types of market research insights influenced some of the following technical research questions: 
- Can walls be highly insulated at a cost that is no higher than the cost of re-siding the walls (and timed to coincide with the re-siding effort to maximize value)?

- What are the major cost drivers?

- Is there an approach to reduce labor time and increase the quality of the installation?

- How does the location of the drainage plane change based on the location of the window mounting?

- What structural requirements are necessary for exterior-mounted windows and doors with the retrofit panels?

- Are there limits to the siding types that should be used with retrofit panels due to weight or building science concerns?

- Are synergistic air-sealing details necessary to complete the system?

- How does the wall cavity moisture change from season to season?

- What do the measured wall cavity moisture data indicate after retrofit panels are installed?

Because finish materials are consistently matters of color, texture, and taste and tend to have a broad price range, counting façade change as discretionary redecorating and decoupling the cost per square foot of this vinyl siding installation from the cost of the energy-efficiency effort (e.g., retrofit insulated panel installation, attic insulation, and air seal) is realistic. 


\section{Retrofit Analysis}

\subsection{Wall Retrofit Cost}

The building that provided the demonstration location required 7,172 $\mathrm{ft}^{2}$ of retrofit insulated panels and new siding material to cover the wood frame exterior walls. A wall weighted average approach to adding thermal resistance to the building was used to retain the exterior appearance of the split-faced CMU walls and leave these exposed for aesthetics and not covered by the retrofit panels. A total average wall R-value of 25 was the stated goal for the project. CMU walls accounted for $17 \%$ of the building's exterior surface area, or $1,467 \mathrm{ft}^{2}$. Retrofit insulated panels were installed on gable end walls above the attic insulation because it was estimated to be the least labor-intensive - and therefore most cost-effective - method of covering the area. The gable end wall square footage is included in the wall area numbers presented here.

Retrofit panels of 4 in. and 6 in. thick were installed - 4 in. at the southwest-facing walls and 6 in. at all northeast and southeast end frame walls. Several 2-in.-thick panels were installed around the entry landings to accommodate egress clearance. The resultant weighted average R-value of the building is R-27 with the use of graphite-enhanced EPS in the retrofit panels.

A request for bids covered all the demonstration project's wall labor and materials other than the retrofit insulated panels and accessories, which were coordinated and provided by the Structural Insulated Panel Association and its members. Three contractors responded with viable proposals ranging from $\$ 60,900$ to $\$ 104,733$. The lowest qualified bidder was selected, as required by the Albany Housing Authority's process. Table 4 shows the actual costs based on the completed project. The Structural Insulated Panel Association provided itemized quantities and costs for panels, adhesives, fasteners, and the dimensional lumber required to edge block the panels.

Table 4. Retrofit Costs-Nail Base Panels

\begin{tabular}{|c|c|c|}
\hline & $\begin{array}{c}\text { Total Cost } \\
\mathbf{( \$ )}\end{array}$ & $\begin{array}{c}\text { Cost/Wall } \mathbf{f t}^{\mathbf{2}} \\
\mathbf{( \$ )}\end{array}$ \\
\hline 2-in. Nail Base Panels & 247 & 0.03 \\
4-in. Nail Base Panels & 9,699 & \\
\hline 6-in. Nail Base Panels & 12,385 & \\
\hline Panel Labor & 15,681 & $3.12^{\mathrm{a}}$ \\
\hline Equipment & 2,400 & 0.33 \\
\hline Design—Panels & \\
\hline Accessories & 1,950 & 0.27 \\
\hline Windows & 4,169 & 0.58 \\
\hline Plumbing Extensions $^{\mathbf{c}}$ & 1,000 & 0.14 \\
\hline Aerogel Insulation & 2,362 & 0.33 \\
\hline Total Cost-Retrofit Panels & 300 & 0.04 \\
\hline
\end{tabular}

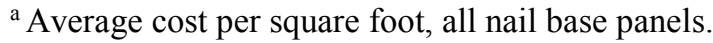

${ }^{\mathrm{b}}$ The cost of the blueprints for the retrofit was split between the panel and siding installation costs.

${ }^{\mathrm{c}}$ Polyvinyl chloride, boiler exhaust pipe, and sprinkler pipe through-wall extensions to accommodate panel thickness. 
Table 5. Retrofit Costs-Siding

\begin{tabular}{|c|c|c|}
\hline & $\begin{array}{l}\text { Total Cost } \\
\text { (\$) }\end{array}$ & $\begin{array}{c}\text { Cost/Wall } \mathrm{ft}^{2} \\
\text { (\$) }\end{array}$ \\
\hline Siding and Accessories, Vinyl & 17,223 & 2.40 \\
\hline Siding Labor & 17,995 & 2.51 \\
\hline Equipment & 1,210 & 0.17 \\
\hline Demo Existing Siding & 5,391 & 0.75 \\
\hline Design $^{a}$ & 1,950 & 0.27 \\
\hline Total Cost—Siding & 43,769 & 6.10 \\
\hline
\end{tabular}

${ }^{a}$ The cost of the blueprints for the retrofit was split between the panel and siding installation costs.

The cost of four new windows is included in the cost to install nail base panels because the panels would have abutted existing glazing at offset walls unless windows of lesser width were located adjacent to these walls. Panel labor averaged $\$ 2.19$, as determined by the certified labor rolls that were submitted to the Albany Housing Authority under Davis Bacon Act requirements and visual inspection of the start and completion dates of the panel installation. The nail base panels were the most expensive line items in this externally added wall thermal resistance retrofit method; they averaged $\$ 3.11 / \mathrm{ft}^{2}$. However, the 6-in. average panel thickness and use of the graphite-enhanced EPS in the panel add to the value of the panels.

This project indicated that the retrofit insulated panel method can be installed in tandem with a siding replacement for about the cost of the siding plus $15 \%$, or $\$ 6.10$ versus $\$ 7 /$ wall $\mathrm{ft}^{2}$. Total cost to reface the building was $\$ 13.10 /$ wall $^{2} \mathrm{ft}^{2}$ (including gables) or $\$ 93,962$ for the seven-unit building.

\subsection{Attic Insulation and Air Sealing Cost}

The building was originally constructed with a flat roof with composite sheathing over $2 \times 8$ rafters. During the 1998 retrofit, gable-shaped roof trusses were installed atop the existing flat roof and the composite sheathing was partially removed to install bathroom fan ducting, blown insulation, and attic access hatches. The air-sealing specifications for the ceiling in the current retrofit were directed at sealing apparent penetrations and the top of the CMU walls with caulk, spray foam, or gaskets.

All existing doors received badly needed maintenance for snug closure at lock cylinders and strike plates and new weather stripping. However, one tenant asked that the weather stripping be removed because closing the door was difficult; it had been removed at the time the final blower door tests were conducted.

New, low-sone bathroom fans with timed controllers were installed to provide exhaust ventilation to each unit. Gaskets were installed behind receptacle and switch plate covers to stem unit-to-unit air movement.

The air sealing effort was performed by the Albany Community Action Partnership with Weatherization Assistance Program funding provided by the U.S. Department of Energy. Table 6 
covers the costs associated with the retrofitting of $3,725 \mathrm{ft}^{2}$ of attic and the 15 doors that were retrofitted in the building.

Table 6. Retrofit Costs-Attic Insulation, Air Sealing, and Ventilation

\begin{tabular}{c|c|c}
\hline & $\begin{array}{c}\text { Total Cost } \\
\mathbf{( \$ )}\end{array}$ & $\begin{array}{c}\text { Cost/Attic } \mathbf{f t}^{\mathbf{2}} \\
\mathbf{( \$ )}\end{array}$ \\
\hline Attic Insulation, R-30 & 1,850 & 2.01 \\
Air Sealing Labor and Material & 1,818 & 0.49 \\
Ventilation Fans, Installed & 4,000 & N/A \\
Total Cost_Attic Insulation, Air & 7,668 & 2.06 \\
Sealing, and Ventilation & & \\
\hline
\end{tabular}

\subsection{Installation}

\subsubsection{Retrofit Insulated Panels}

The building air sealing success of the retrofit panel method lies chiefly in the retrofit insulated panel's characteristic of being a single component that provides the subsurface requirements for both insulation and siding-R-value and a nailing base. The component can provide an air seal with perimeter spray foam or mastic adhesive applied to OSB edges while the panel is being set into place.

All the known industry best practices can be used to address finishes to the wall after the panels are installed. Moisture barrier and drainage plane are provided by a weather-resistive barrier. Flashing at wall penetrations, planar interruptions (such as the porch roof brackets shown in Figure 9), and terminations follow established methods for sheathed light frame walls that are well known in the industry.

One-piece rear stairways supported by a single pipe column welded to the landings and cast into concrete footings at grade precluded removal of the rear stairways to access band boards below the patio doors. The band board area below the doors and behind the stair landings could not be fitted with nail base panels because of insufficient clearance. To add insulation in these areas, band boards behind rear stair landings were first covered with 2/5-in. Spaceloft aerogel fabric for thermal and moisture resistance, ${ }^{5}$ then counterflashed with a custom-fabricated pan flashing of break metal that redirected the drainage plane to the surface of the nail base panel. The aerogel fabric provides thermal resistance of R-4.8 and is water and fire resistant (Figure 10). Figure 11 shows the completed rear entryway.

\footnotetext{
${ }^{5}$ www.aerogel.com/products-and-solutions/all-insulation-products/
} 


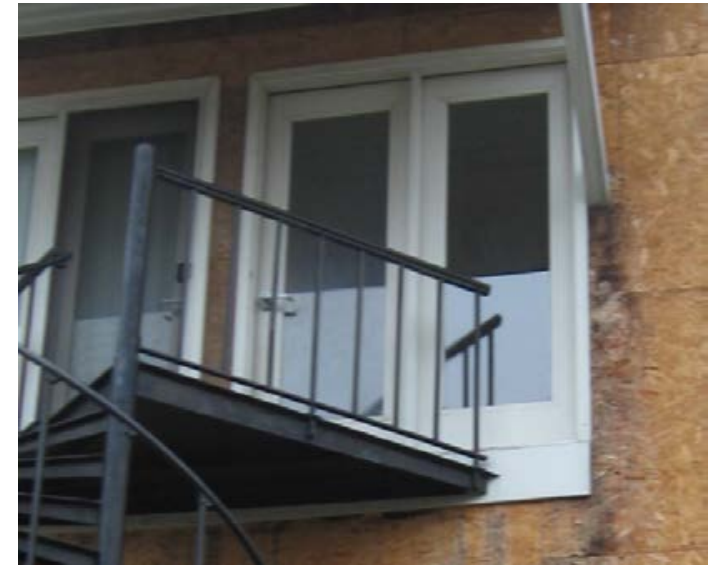

Figure 9. Rear patio doors and stairs at siding removal phase

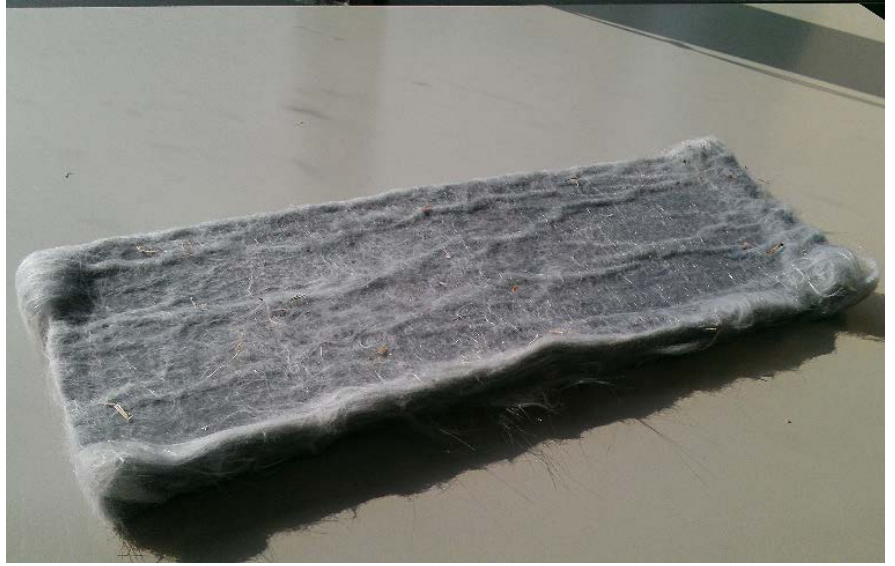

Figure 10. Aerogel insulation, $10 \mathrm{~mm}$

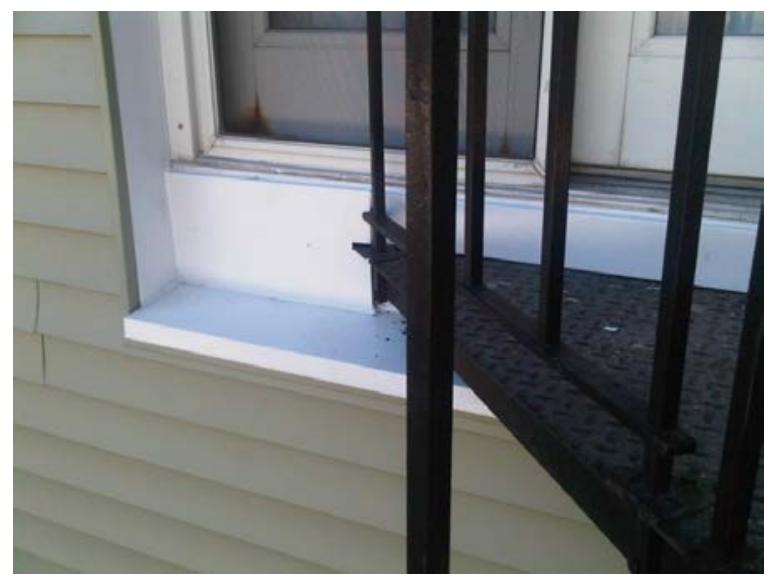

Figure 11. Completed rear entry at stair landing

To simplify the drainage plane detail, windows were removed and reinstalled at the new exterior surface of the wall. Nail base panel thicknesses are sized for dimensional lumber inserts at panel edges; therefore, window frame extensions were fashioned with $2 \times 4$ or $2 \times 6$ dimensional lumber boxes set on edge against the wall framing and secured with SIP screws through the 1.5in. edge of the board (Figure 12). The holes were predrilled and screws were fastened through the new window frame into the framing of the wall. A 1.5-in. recess was cut in the foam of the nail base panels adjacent to the window opening, and the OSB of the panel was set to overlap the new frame. The OSB was sealed and secured to the new window frame using the same method employed at building edges. Flashing and weather-resistive barrier were subsequently installed around the window by the same methods used in new construction (Figure 13 and Figure 14). 


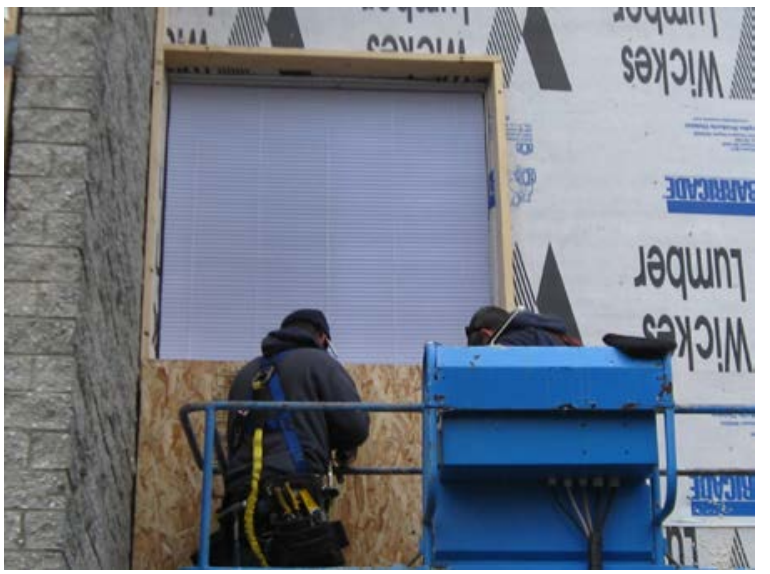

Figure 12. Framing installed around window opening

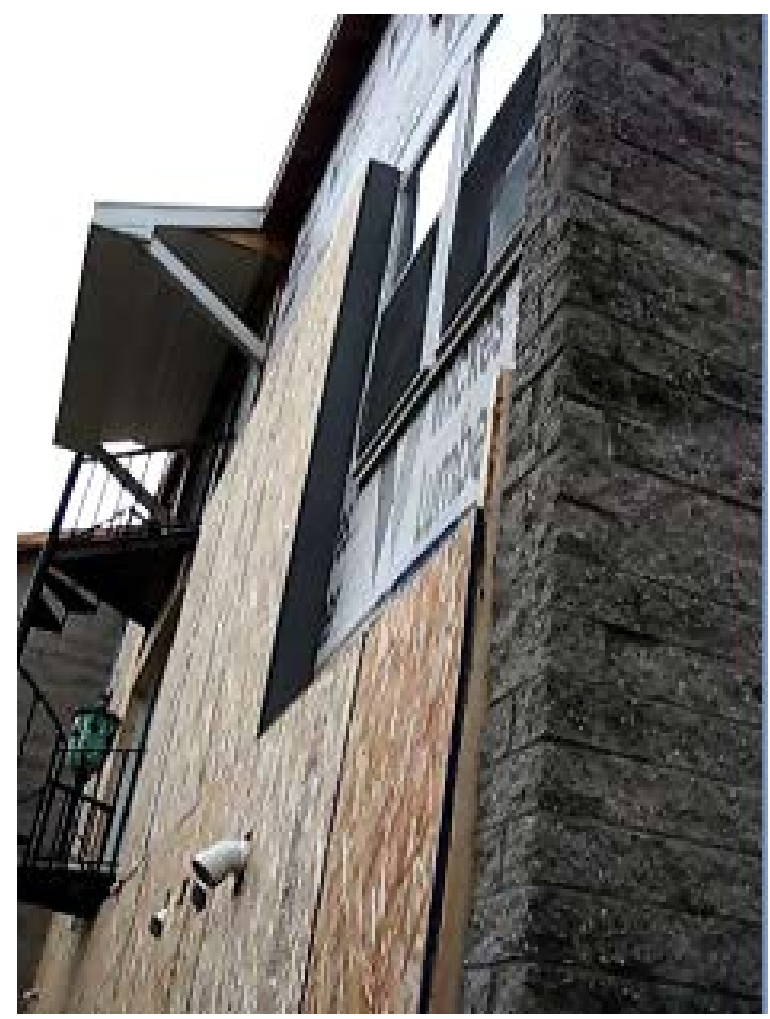

Figure 13. Rear windows prior to removal

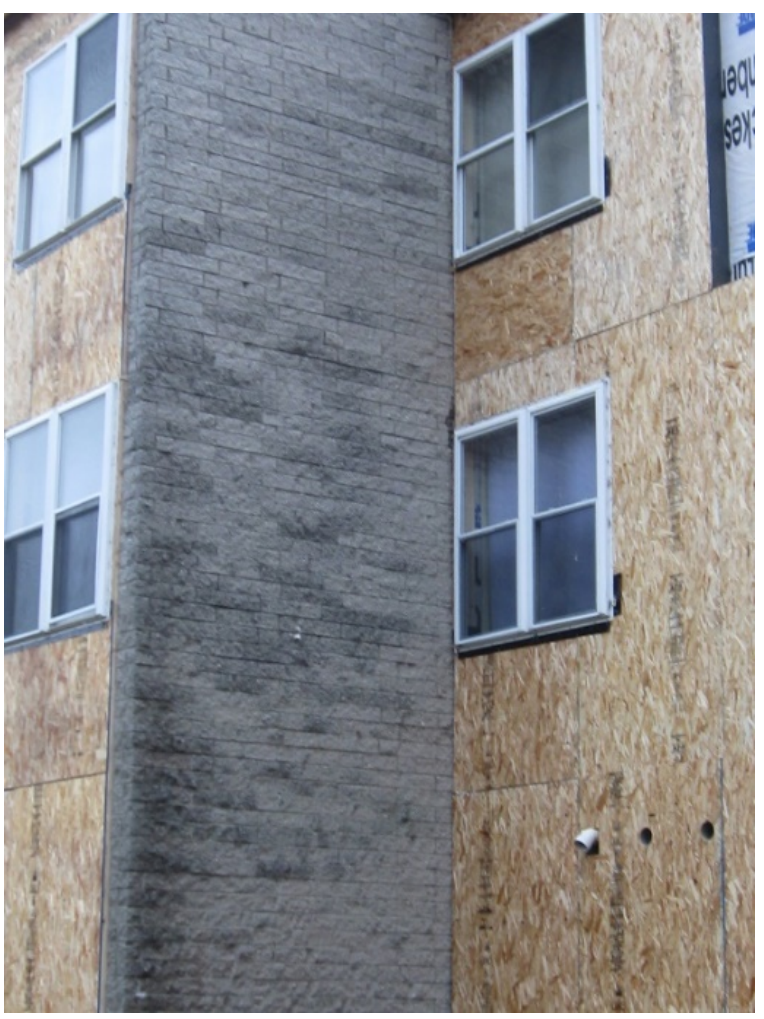

Figure 14. Rear windows after reinstallation

The nail base panels were fastened per a pattern engineered for the specific installation. Testing reports published by fastener manufacturers (TRUFAST 2013) provide guidelines for the panel applications. Siding manufacturers provide fastening instructions for use of their products over an OSB nailing surface (Certainteed 2013). 
The exterior details used to make nail base panels weather resistant are widely practiced in new construction and remodeling jobs, so the installation crew did not need to learn new techniques. The vinyl siding is expected to be as maintenance free as the old siding.

The house wrap was left in place in this project (Figure 15 and Figure 16). The house wrap helps protect the structure after the siding is removed and while the panels are being installed. Because most house wrap products are more vapor permeable than EPS foam insulation or OSB sheathing, the house wrap does not significantly change the moisture characteristics of the wall assembly. Leaving the house wrap in place is not required but it is the most cost-effective measure, partly because the product does not need to be disposed.

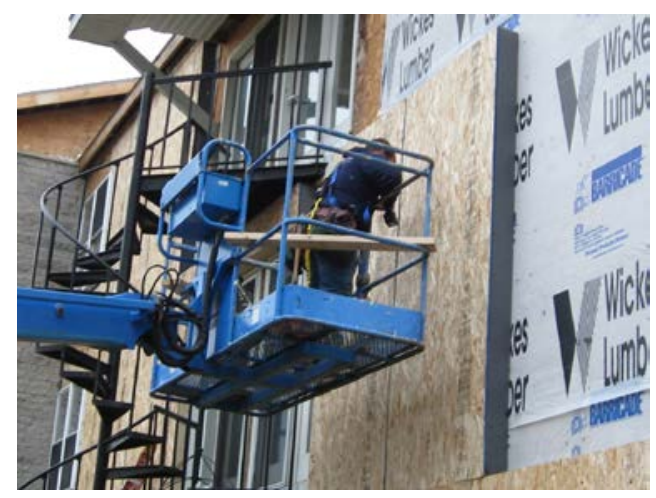

Figure 15. Installing a 6-in. retrofit panel

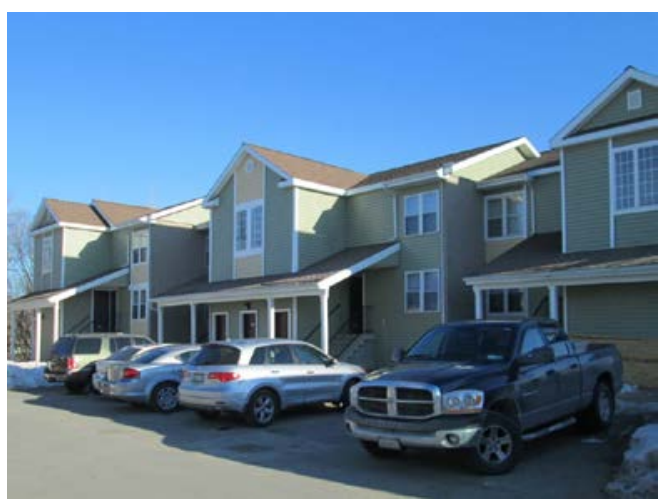

Figure 16. Building front after retrofit

\subsubsection{Attic Insulation and Air Sealing}

In addition to the panel and siding installation, air sealing in the attic, exterior door weatherstripping, additional insulation, and a ventilation strategy were planned. The Albany Community Action Partnership was recruited to finish the weather sealing details because of its expertise in this area. Accessible attic locations such as at the top of the CMU party walls were air sealed, and blown insulation was installed to achieve R-49 for the attic floor. 


\section{Results}

\subsection{Affordability}

A major goal of this project was to double the R-value of the walls for the same cost as re-siding the building. The result came within $15 \%$ of meeting that cost goal. The line item contribution of the project's components to the total project cost is depicted in Figure 17.

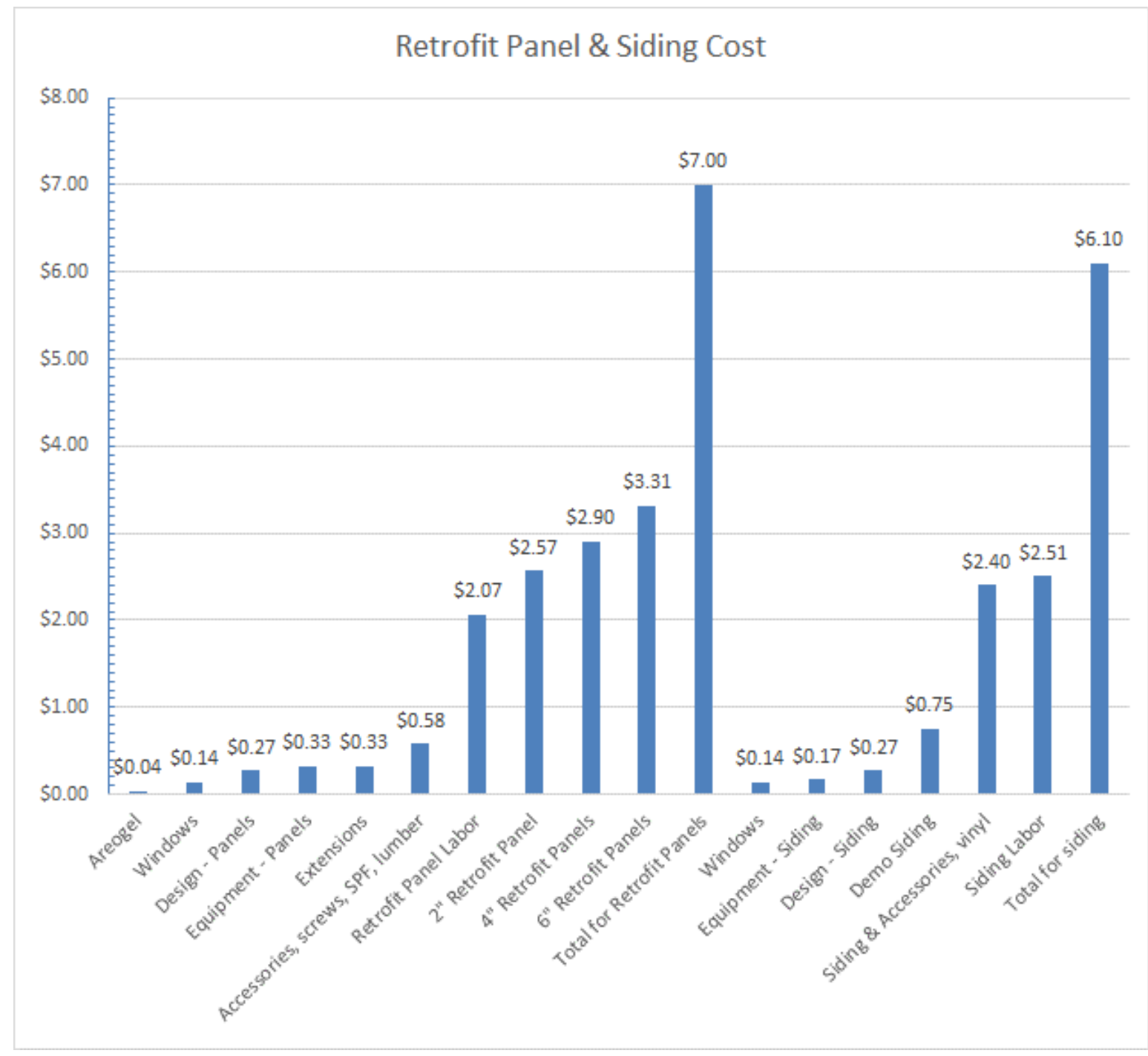

Figure 17. Comparison of costs for retrofit panels and costs associated with re-siding

The cost associated with air sealing and insulating the attic, providing for mechanical ventilation, and tightening door sealing amounted to $\$ 2.06 / \mathrm{ft}^{2}$ of ceiling area.

Summing the surface areas of the insulated walls and ceiling equals $10,892 \mathrm{ft}^{2}$. Then, summing the costs of the wall and ceiling retrofits amounts to $\$ 101,630$, including the siding, or cosmetic facelift. The result is a cost of $\$ 9.33 / \mathrm{ft}^{2}$ for the entire project. 


\subsection{Measured Moisture Characteristics of the Assembly}

The Neopor EPS that was used in the panels is a Class II vapor retarder in the thicknesses that were applied and slows the moisture diffusion through the retrofitted wall assembly. The exterior cladding and the success of the flashing and weather-resistive barrier installation will provide the building's defense against bulk water intrusion.

With the addition of the retrofit panels, the dynamic moisture movement through, and accumulation in, the wall building materials (i.e., framing, original wood sheathing, new retrofit panel OSB sheathing) will change from its original characteristics based on interior and exterior moisture levels.

To monitor the moisture performance, OmniSense S-900-1 sensors that measure temperature, $\mathrm{RH}$, and moisture content (MC), were placed around the building; within each unit, within selected original exterior wall cavities, and within selected retrofitted nail base panels (Table 7).

Table 7. Locations and Identifications of Sensors Installed in the Building

\begin{tabular}{|c|c|c|c|c|}
\hline Sensor ID & Unit ID & $\begin{array}{c}\text { Location } \\
\text { Orientation }\end{array}$ & $\begin{array}{c}\text { In } 2 \times 4 \text { Wall } \\
\text { Sheathing }\end{array}$ & $\begin{array}{c}\text { In Nail Base } \\
\text { Panel }\end{array}$ \\
\hline 195500A1 & 150A Basement & Conditioned & & \\
\hline 169602AF & $150 \mathrm{~A}$ & Conditioned & & \\
\hline $16960211^{\mathrm{a}}$ & $150 \mathrm{~B}$ & Conditioned & & \\
\hline 0D120242 & $150 \mathrm{~B}$ & Conditioned & & \\
\hline $169603 \mathrm{D} 7$ & $151 \mathrm{~A}$ & Conditioned & & \\
\hline $169603 \mathrm{C} 4$ & 152A Basement & Conditioned & & \\
\hline 1696038B & $152 \mathrm{~A}$ & Conditioned & & \\
\hline 16960351 & $152 \mathrm{~B}$ & Conditioned & & \\
\hline $169603 \mathrm{~F} 6$ & 153A Basement & Conditioned & & \\
\hline 1696034B & $153 \mathrm{~A}$ & Conditioned & & \\
\hline $1696015 E$ & $153 \mathrm{~B}$ & Conditioned & & \\
\hline 169603EC & $150 \mathrm{~A}$ & Northeast & $1^{\text {st }}$ level rear & \\
\hline 169601BE & $150 \mathrm{~A}$ & Southwest & $1^{\text {st }}$ level front & \\
\hline $169602 \mathrm{B3}$ & $150 \mathrm{~B}$ & Northeast & $2^{\text {nd }}$ level rear & \\
\hline 1955016D & $150 \mathrm{~B}$ & Northeast & & $2^{\text {nd }}$ level rear \\
\hline $169602 \mathrm{CC}$ & $150 \mathrm{~B}$ & Southwest & $2^{\text {nd }}$ level front & \\
\hline $1955008 \mathrm{C}$ & $150 \mathrm{~B}$ & Southwest & & $2^{\text {nd }}$ level front \\
\hline $169603 \mathrm{C} 9$ & $151 \mathrm{~A}$ & Northeast & $2^{\text {nd }}$ level rear & \\
\hline 169601A1 & $151 \mathrm{~A}$ & Southwest & $2^{\text {nd }}$ level front & \\
\hline 19550149 & $151 \mathrm{~A}$ & Southwest & & $2^{\text {nd }}$ level front \\
\hline 16960395 & $152 \mathrm{~A}$ & Southwest & Weather station & \\
\hline 16960259 & $152 \mathrm{~A}$ & Northeast & $1^{\text {st }}$ level rear & \\
\hline 16960298 & $152 \mathrm{~A}$ & Southwest & $1^{\text {st }}$ level front & \\
\hline 16960247 & $152 B$ & Northeast & $2^{\text {nd }}$ level rear & \\
\hline 195500DC & $152 \mathrm{~B}$ & Northeast & & $2^{\text {nd }}$ level rear \\
\hline
\end{tabular}




\begin{tabular}{|c|c|c|c|c|}
\hline Sensor ID & Unit ID & $\begin{array}{c}\text { Location } \\
\text { Orientation }\end{array}$ & $\begin{array}{c}\text { In } 2 \times 4 \text { Wall } \\
\text { Sheathing }\end{array}$ & $\begin{array}{c}\text { In Nail Base } \\
\text { Panel }\end{array}$ \\
\hline $169601 \mathrm{AF}$ & $152 \mathrm{~B}$ & Southwest & $2^{\text {nd }}$ level front & \\
\hline 19550109 & $152 B$ & Southwest & & $2^{\text {nd }}$ level front \\
\hline 16960309 & $153 \mathrm{~A}$ & Northeast & $1^{\text {st }}$ level rear & \\
\hline $169602 \mathrm{~A} 2$ & $153 \mathrm{~A}$ & Southwest & $1^{\text {st }}$ level front & \\
\hline 16960208 & $153 \mathrm{~B}$ & Northeast & $2^{\text {nd }}$ level rear & \\
\hline $195500 \mathrm{~F} 6$ & $153 \mathrm{~B}$ & Northeast & & $2^{\text {nd }}$ level rear \\
\hline 169602D1 & $153 \mathrm{~B}$ & Southwest & $2^{\text {nd }}$ level front & \\
\hline
\end{tabular}

${ }^{a}$ Replaced by 0D120242 on 3/10/15 because it was not transmitting.

The manufacturer stated accuracy for these sensors is $\pm 2 \% \mathrm{RH}$ and $\pm 0.3^{\circ} \mathrm{C}$; these values were verified by Wiehagen and Kochkin (2012). Data measurements were recorded every 15 minutes. Measurements of the wood MC, by building sections between CMU walls, are reported by the graphs in Figure 18 to Figure 20 for the duration of the monitoring (the retrofit panels were installed during the 2013-2014 winter). The graphs indicate average daily sheathing MC ranges generally between $6 \%$ and $11 \%$; a few sensors read slightly higher than $14 \%$. The maximum MC recorded is much lower than the $20 \%$ minimum threshold (Carll and Highley 1999) and is considered normal. Because $\mathrm{MC}$ varies with ambient $\mathrm{RH}$ and with the airtightness of the building, these conditions were monitored through the 2014-2015 heating season.

A small but notable change occurred in the sheathing $\mathrm{MC}$ from before the retrofit panel installation to after. Before the retrofit, the $\mathrm{MC}$ readings generally ranged from approximately $9 \%$ to less than $15 \%$, whereas after the retrofit, the $\mathrm{MC}$ readings ranged from around $6 \%$ to less than $10 \%$. This result implies that no negative moisture effects are indicated with the addition of the retrofit panels.

RH inside each unit generally remained lower than $40 \%$ during the heating season (Figure 21). ASHRAE (2015) indicates that an indoor RH range between $30 \%$ and $60 \%$ minimizes the indoor growth of allergenic or pathogenic organisms.

$\mathrm{RH}$ is a meaningful performance metric because as it increases in a wall cavity, the potential for condensation of water vapor on the outermost surface of OSB panels also increases. As RH increases, the dew point temperature moves closer to the ambient temperature, which makes RH a suitable metric for condensation potential. Comparison plots for the sensors in the wall cavities and the temperature difference between the sheathing temperature and the dew point temperature are shown in Figure 22 through Figure 24. Negative chart values (when the dew point temperature exceeds the sheathing temperature) indicate a higher cavity dew point than cavity air temperature near the OSB sheathing, with a resultant likelihood of condensation. This case was not noted in any of the wall panels or cavities. 
12

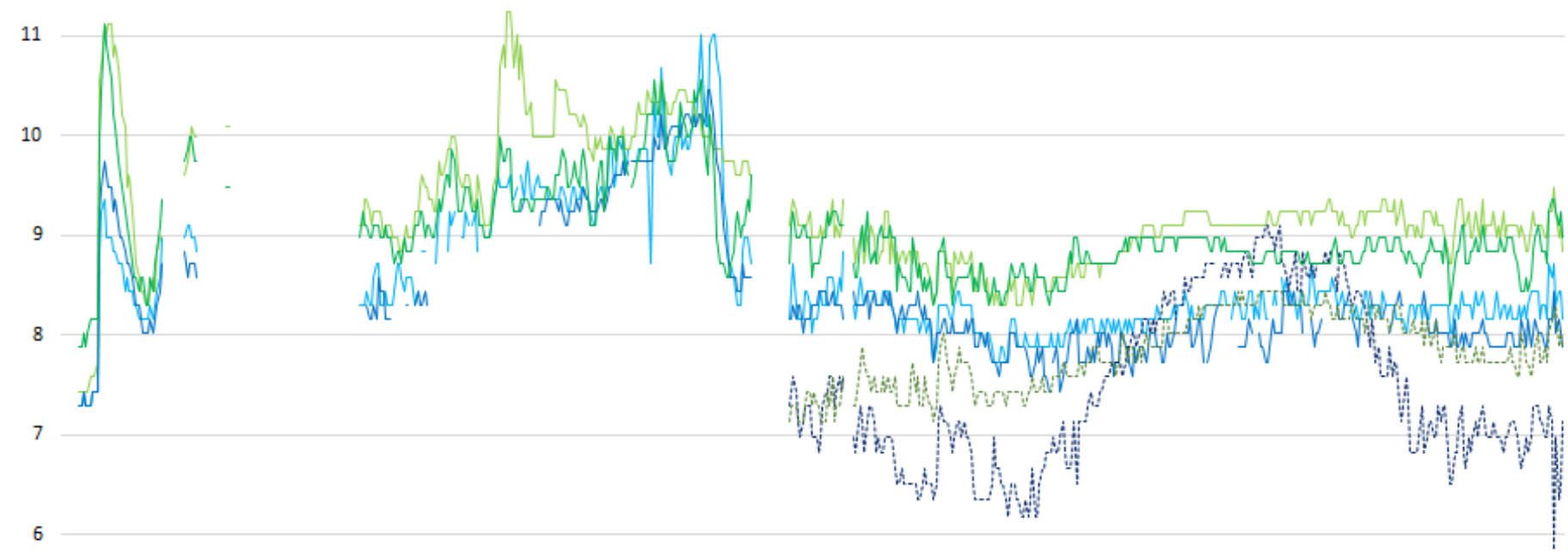

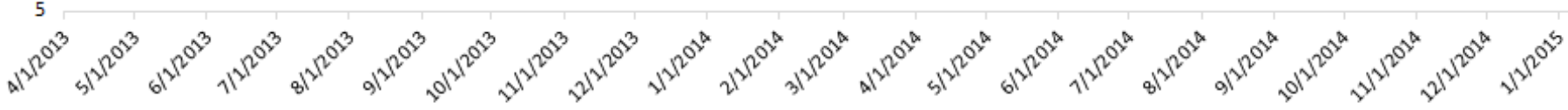

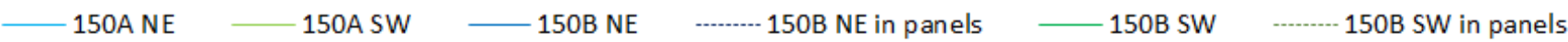

Figure 18. OSB moisture content-right section of building, units 150 basement, $150 \mathrm{~A}$, and 150B 


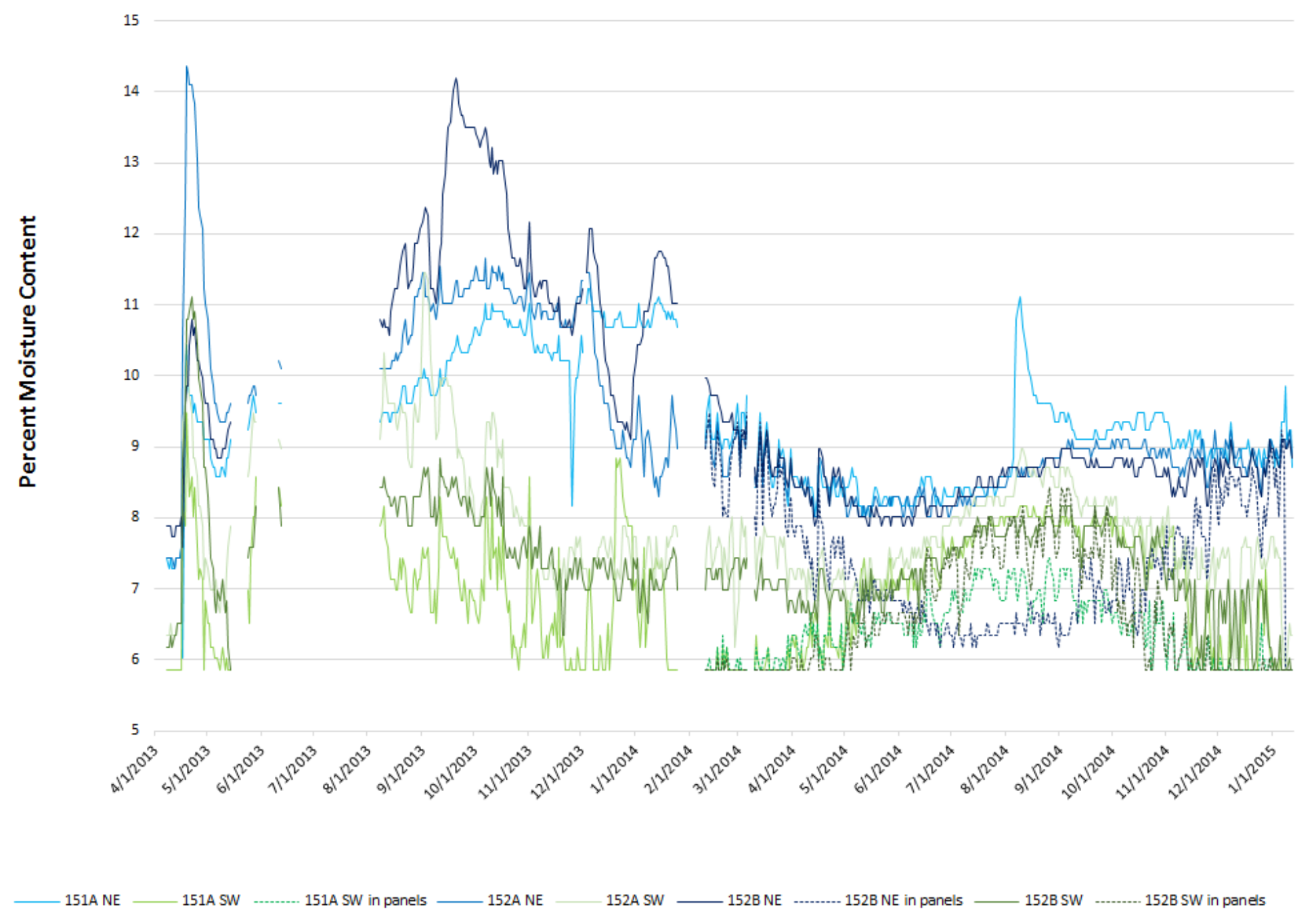

Figure 19. OSB moisture content-center section of building, units 152 basement, 152A, 152B, and 151A 
13

12

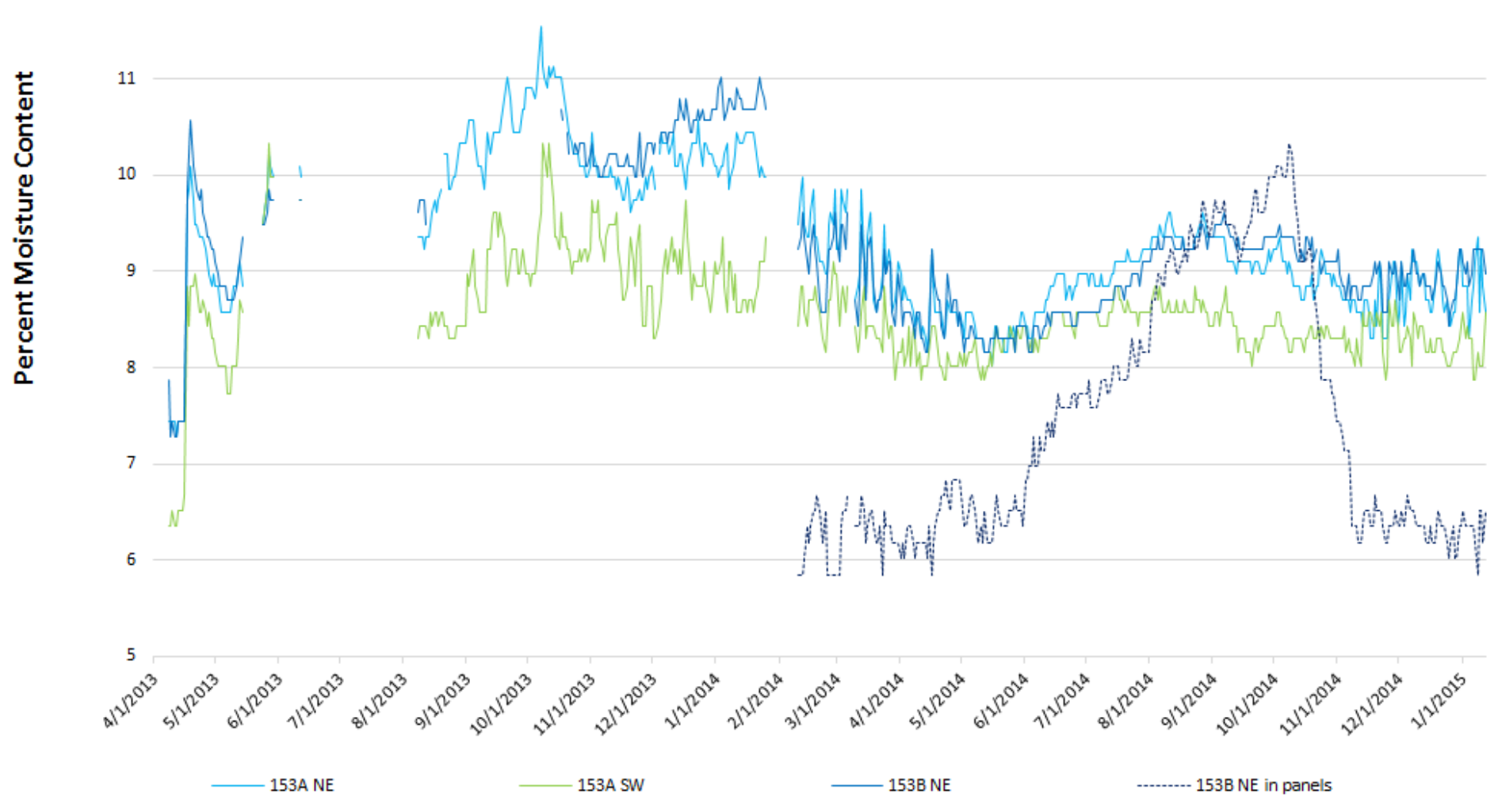

Figure 20. OSB moisture content-left section of building, units 153 basement, 153A, and 153B 


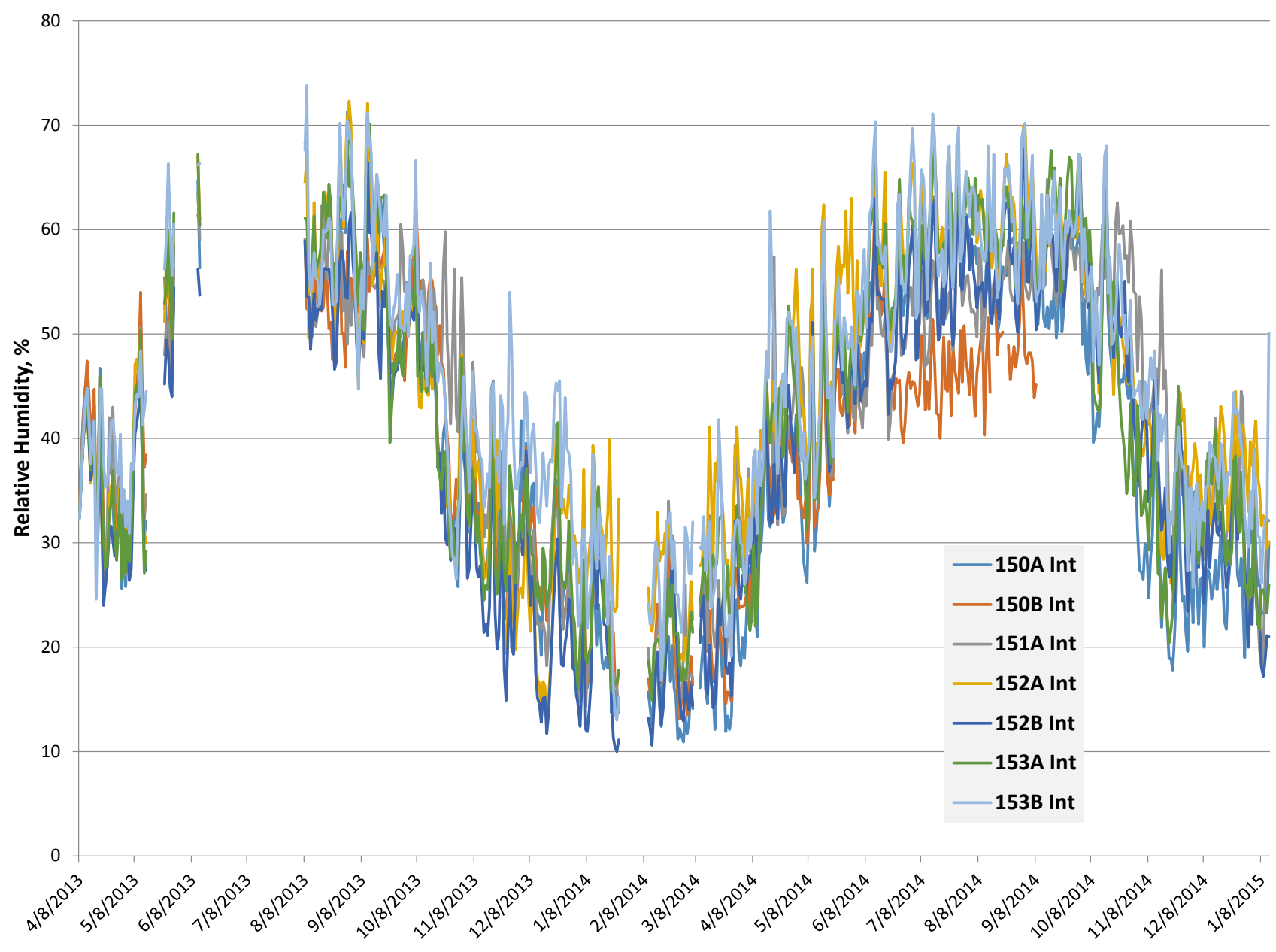

Figure 21. RH within the units 
60

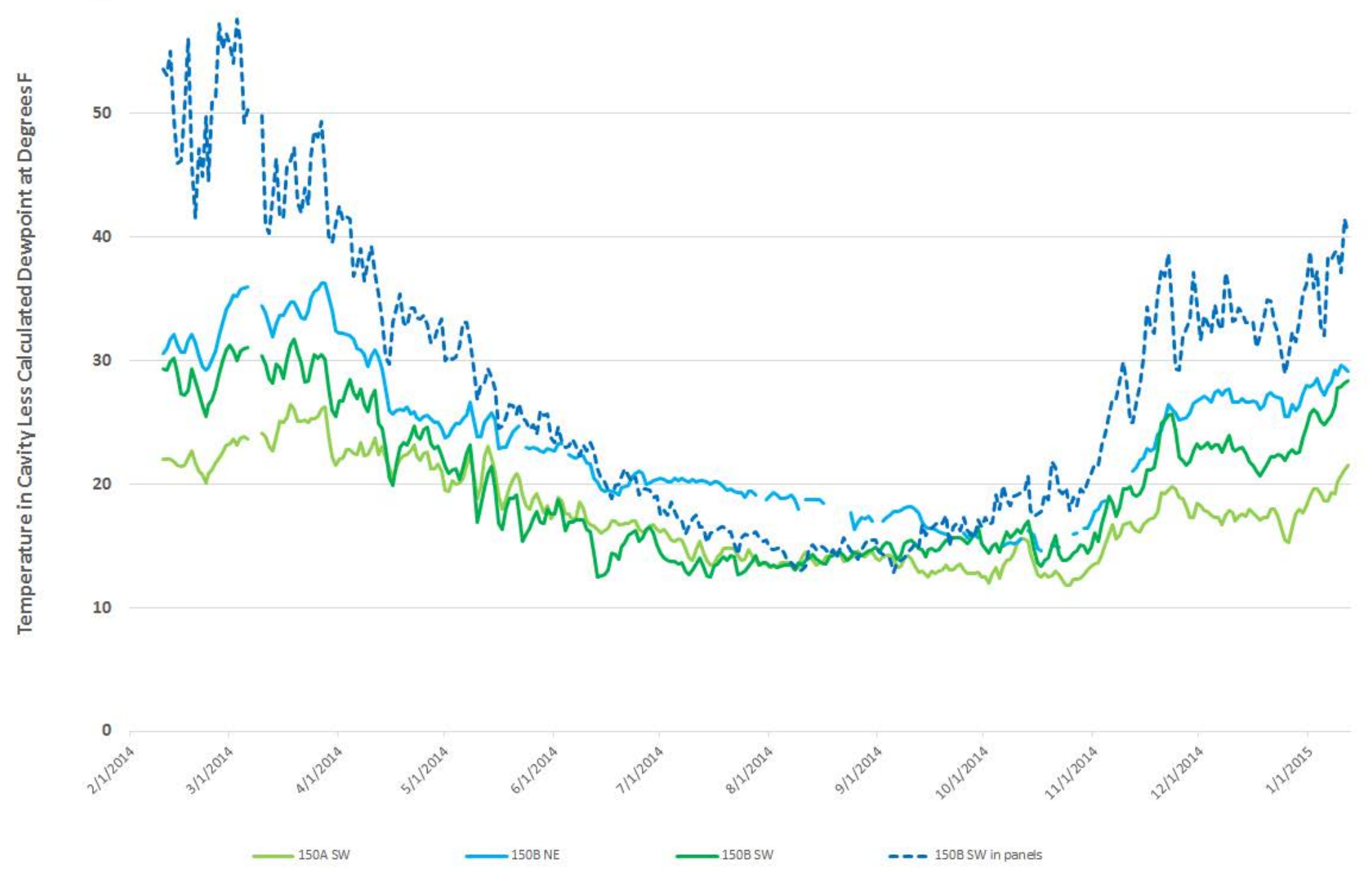

Figure 22. Condensation potential right section of building 


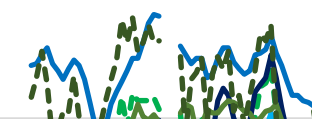

20 N

鹿

돈

竞

10

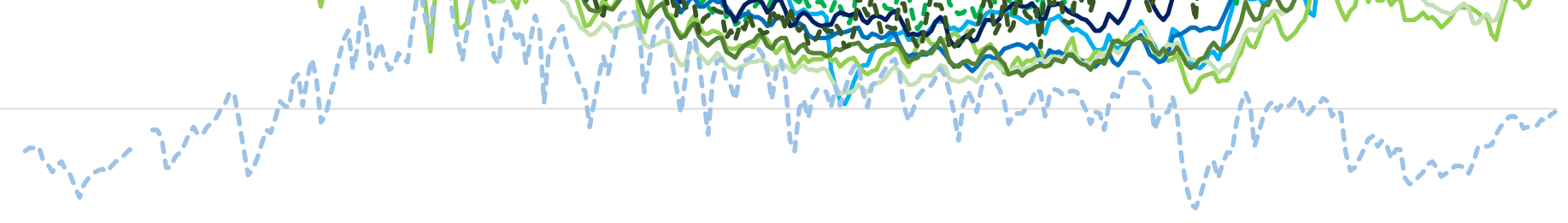

0

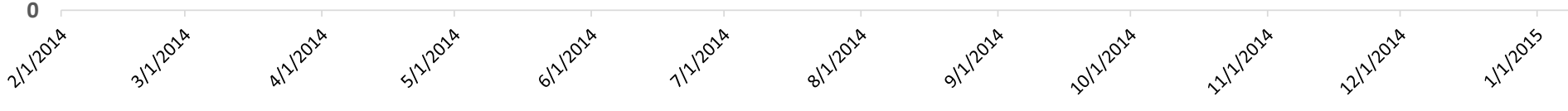

Figure 24. Condensation potential middle section of building 
ENs. ofparpruen of

Energy Efficiency \&

Renewable Energy

60
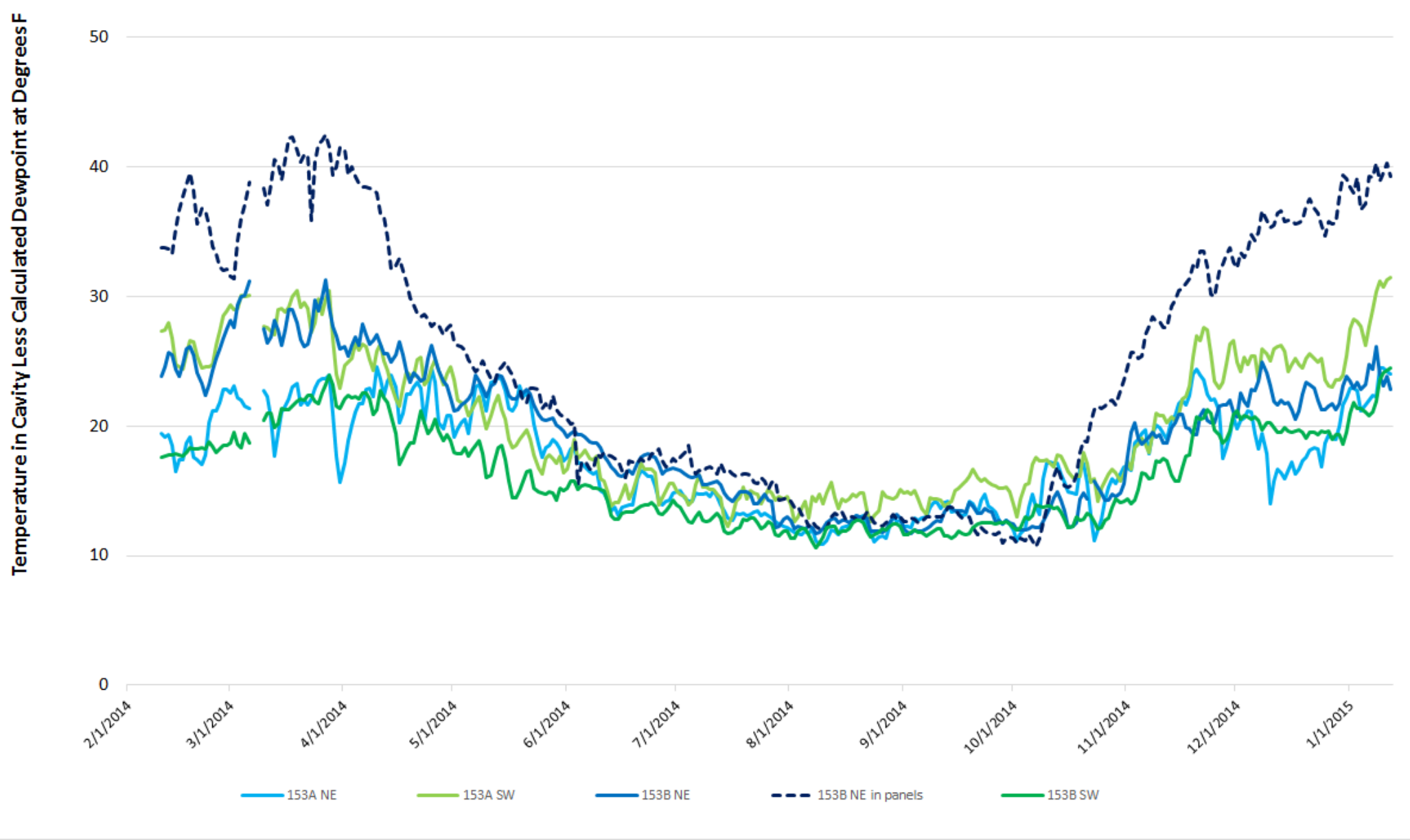

30 


\subsection{Building Air Infiltration Reduction}

The blower door test zone consisted of three two- and three-unit towers separated by nongrouted CMU block walls. Visual inspection from the abandoned basement units indicated that the CMU blocks had been penetrated by receptacle boxes installed in the party walls of all units (Figure 25).

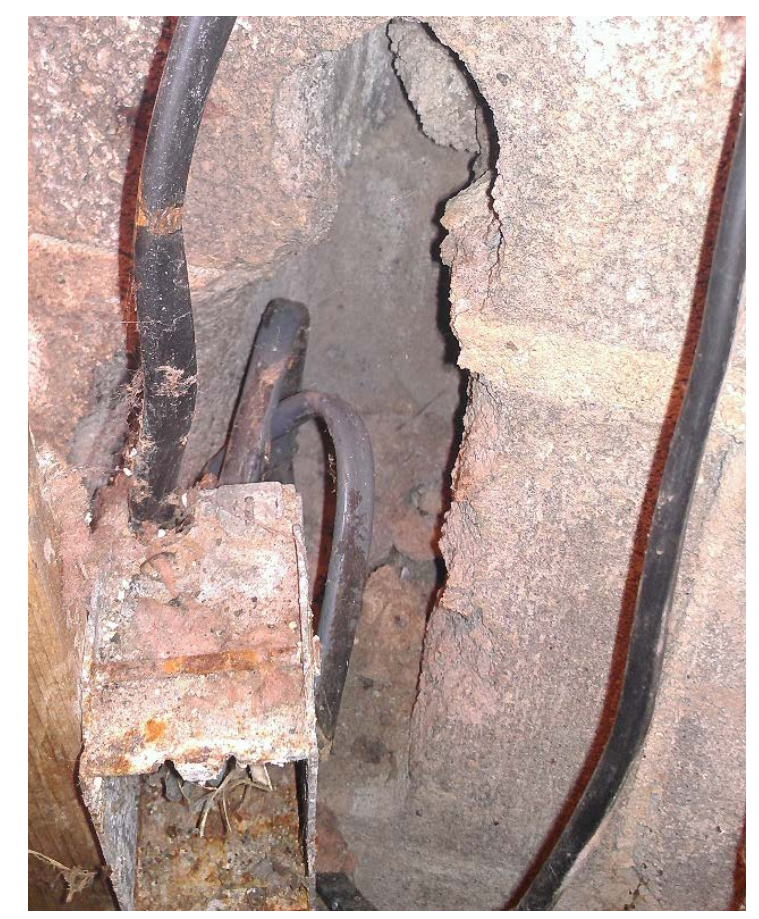

Figure 25. Abandoned basement receptacle at $\mathrm{CMU}$ wall

For the airtightness test, three blower door units were used to depressurize to 50 Pascals. Each of the end towers' three apartments were first tested individually and then simultaneously. The difference between the combined individual depressurized leakage measurement and the simultaneous depressurized leakage measurement provided an estimate of the leakage between the adjacent units. The total leakage measured during the simultaneous test provides an estimate of the leakage to the outside.

Although the building towers were separated from each other by the CMU walls, the simultaneous test did not qualify as a fully guarded blower door tests due to the leakage through CMU walls. Therefore, leakage to the outside could be slightly overstated. A fully guarded blower door test would require a prohibitive number of blower door units.

The four units in the middle tower (two lower units stacked with a third level of two units) were tested in multiple combinations to calculate the difference of the four adjacent units using only three blower door fans. The following combinations were tested individually and simultaneously: (1) basement, first-floor, and one second-floor unit, (2) basement and both second-floor units, and (3) first-floor and both second-floor units. 
Results of all blower door tests before and after the implementation of the air-sealing measures are shown in Table 8. 
Table 8. Building Air Leakage Test Results

\begin{tabular}{|c|c|c|c|c|c|c|c|c|}
\hline & & \multicolumn{3}{|c|}{ Before Condition } & \multicolumn{4}{|c|}{ Final after Wall Retrofit and Attic Insulate/Seal } \\
\hline \multicolumn{2}{|c|}{ Unit } & Measured & $\begin{array}{c}\text { Net } \\
\text { Leakage } \\
\text { Out }^{\mathrm{a}}\end{array}$ & $\begin{array}{c}\text { Before } \\
\text { ACH50 } \\
\text { Per Unit }\end{array}$ & $\begin{array}{c}\text { Total } \\
\text { Leakage }\end{array}$ & $\begin{array}{l}\text { Leakage to } \\
\text { Adjacent }\end{array}$ & $\begin{array}{c}\text { Net } \\
\text { Leakage } \\
\text { Out }\end{array}$ & $\begin{array}{c}\text { Final } \\
\text { ACH50 Per } \\
\text { Unit }\end{array}$ \\
\hline \multirow{3}{*}{ End Tower } & $\begin{array}{c}153 \\
\text { Basement }\end{array}$ & 2,491 & 1,391 & 10.1 & 2,550 & 1,100 & 1,450 & 10.5 \\
\hline & $153 \mathrm{~A}$ & 1,607 & 923 & 6.7 & 1,219 & 684 & 535 & 3.9 \\
\hline & 153B & 1,773 & 1,073 & 7.8 & 1,500 & 700 & 800 & 5.8 \\
\hline \multirow[t]{2}{*}{ Middle Tower } & $\begin{array}{c}152 \\
\text { Basement }\end{array}$ & 3,729 & 2,099 & 10.0 & 3,300 & 1,630 & 1,670 & 8.0 \\
\hline & $152 \mathrm{~A}$ & 2,680 & 880 & 4.2 & 2,200 & 1,800 & 400 & 1.9 \\
\hline \multirow{5}{*}{ End Tower } & $152 \mathrm{~B}$ & 1,934 & 980 & 9.1 & 1,699 & 954 & 745 & 6.9 \\
\hline & $151 \mathrm{~A}$ & 2,228 & 913 & 8.5 & 1,700 & 1,315 & 385 & 3.6 \\
\hline & $\begin{array}{c}150 \\
\text { Basement }\end{array}$ & 2,445 & 1,495 & 10.7 & 2,800 & 950 & 1,850 & 13.3 \\
\hline & $150 \mathrm{~A}$ & 1,851 & 798 & 5.7 & 1,690 & 1,053 & 637 & 4.6 \\
\hline & $150 \mathrm{~B}$ & 2,484 & 1,593 & 11.4 & 1,854 & 891 & 963 & 6.9 \\
\hline \multicolumn{2}{|c|}{ Total } & 23,222 & 12,145 & & 20,512 & 11,077 & 9,435 & \\
\hline \multirow{2}{*}{\multicolumn{3}{|c|}{$\begin{array}{l}\text { Air Seal Improvement } \\
\text { Building Leakage to Outside (ACH50) }\end{array}$}} & & & & & $22.3 \%$ & \\
\hline & & & \multicolumn{2}{|c|}{8.3} & \multicolumn{4}{|c|}{6.4} \\
\hline
\end{tabular}

${ }^{a}$ Using leakage to adjacent units results from final test. 
The improvement in airtightness by $22 \%$ (from 8.3 to 6.4 ACH50) fell short of expectations. The air sealing was performed by a professional weatherization crew that followed standard procedures and was bound by protocols for the programs that support those efforts. The final airsealing measures were selected by the weatherization company based on the calculated expected payback. Some of the air-sealing measures suggested by PHI were not implemented because those measures did not meet the weatherization program's criteria for cost-effectiveness. For this type of building, the standard methods for selecting air-sealing measures may not consistently result in the expected level of improvement and have the potential to miss significant opportunities to improve the performance of the building. In large part, the demonstration building's design, construction, and use contributed to this result due to:

- A wide range of architectural features including split-face block walls abutted by vertical adjacent walls

- The configuration and details of the gabled roof that was constructed as part of a previous retrofit converting the original flat roof to a gable roof; during that retrofit some materials from the flat roof were removed; numerous air leakage pathways were probably created as part of the retrofit

- Aging windows that were difficult or impossible to fully close

- Installation of the retrofit nail base panels during weather that was consistently below freezing leading to a less-effective air seal of the edges

- The inability at project outset to identify key leakage wall and basement pathways using standard testing and diagnostics methods.

These results also confirm that the nail base panel installation as a single measure, particularly in some building types, does not provide a sufficient air seal to meet rigorous air-sealing targets and has to be implemented as part of a customized package of measures.

The contribution to air leakage by stack effect also became apparent during the final blower door tests, which revealed that basements communicated directly with second levels via a common stairwell and possible hidden chimneys that contain pipes for the retrofitted fire sprinkler system. CMU walls were capped in the attic per the air-sealing scope of work; however, the effectiveness of such air sealing is undetermined. 


\section{Conclusions and Discussion}

\subsection{Lessons Learned}

\subsubsection{Factors that Influenced Cost Positively}

The Neopor ESP insulation provided added R-value over generic EPS-R-4.5 versus R-3.8. The versatility in available thickness of retrofit insulated panels compensates for EPS' lower R-value per inch than other rigid foams because orders can be placed for the panel thickness that meets the required R-value. And, by specifying a graphite-enhanced EPS, the panels came to within $10 \%$ of the R-value per inch of extruded polystyrene; R-4.5 versus R-5 (BASF 2014).

Standardized panel size of $4 \mathrm{ft} \times 8 \mathrm{ft}, 10,12$, etc. allows maximizing placement labor, spanning common air leakage areas with single components, such as walls and band boards, and ultimately, potential off-the-shelf sales capability. (Currently retrofit insulated panels are special ordered from SIP panel manufacturers.) ${ }^{6}$

Single-component installation kept labor costs at $\$ 3.19 / \mathrm{ft}^{2}$. Further investigation into the optimal panel thickness and the most favorable crew size is warranted. The three- to four-man crew that installed this job site was understaffed due to the use of the lift equipment. A cutter, material feeder, and two installers in the bucket were required to keep the team working rather than having some of the crew waiting due to a bottleneck.

\subsubsection{Factors that Hampered Affordability}

Inner doorframes that remain at the plane of the building's original exterior present a flashing logistics problem. If left in place, flashing at openings must be retrofitted to extend to the new plane created by the retrofit insulated panel, or a secondary drainage plane must be established between existing exterior and new exterior surfaces. A drainage plane behind the retrofit insulated panels would undermine the air seal that can be created with the new OSB surface and solid wood blocking at panel edges. To skirt the complexity of details, windows on the demonstration building were relocated to the new exterior surface plane. The decision entailed several thousand dollars in labor, flashing, and a reserve for breakage, but the new location of the windows provided a more durable installation and future access for maintenance or replacement. Ideally, a remodel that would include re-siding and new windows would leave fewer costs directly associated with the wall insulation effort.

Constructability issues, such as maintaining clearances and step flashing where a wall abuts an entryway roof, surfaced as soon as the retrofit was underway. As with all high-R-value installations, the thickness of the assembly limited some applications at this demonstration site. Front entry landings and rear band boards behind iron circular stairways required 1-in. insulation board or 10-mm aerogel fabric insulation to accommodate clearances in these areas. Retaining the continuity of an air barrier was difficult in these areas.

The 1998 retrofit of the building and the abandonment of the basement apartments included filling the basement window openings with new framing that resulted in uneven exterior wall surfaces (some areas were as much as 2 to 3 in. out in $8 \mathrm{ft}$.) These areas were difficult to bridge

\footnotetext{
${ }^{6}$ www.sips.org.
} 
successfully with the 6-in.-thick panels, and some retrofit panel edges were $1 / 8$ in. out of plane after installation. These edges were treated with panel adhesive. A less-rigid panel, perhaps a 4in. retrofit panel, could have provided more flexibility in bridging the wall plane variances. Reworking the planar irregularities of the existing frame prior to nail base panel installation is an alternative.

Mounting the learning curve handicapped the team of skilled carpenters who spent 2 days learning the ropes with a Structural Insulated Panel Association trainer. In 2 days approximately $600 \mathrm{ft}^{2}$ (or about 194 -in. panels) were installed by an average-sized crew of three. A similar pace was observed for the installation of the 6-in. retrofit panels over a week-long period. An experienced crew typically performs at two to three times that level of production in favorable conditions.

\subsubsection{Other Positive Factors}

EPS, measured by its life cycle, is a better environmental choice than extruded polystyrene and spray polyurethane foam (Wilson 2010), because it is a closed-cell product that is made up of $90 \%$ air and requires about $85 \%$ fewer petroleum products for processing than other rigid foams. Pentane, which EPS manufacturers use instead of hydrofluorocarbons for bead expansion, has a decreased global warming potential over the hydrofluorocarbons used in other foam products (EPA 2011).

\subsubsection{Details that Merit Emphasis}

The size and location of the continuous mastic or spray polyurethane foam beads shown in the guide's details are extremely important, as is the temperature of the panels and the air. One of the lessons learned from this project which took place from Dec. 2013 through Jan. 2014, over 2 months during which 2,547 heating degree days (HDDs) and average daily high temperatures of $32^{\circ} \mathrm{F}$ were recorded, ${ }^{7}$ is that the air seal that can be provided by these panels relies on the panel's OSB surface adhered to the adjacent panel's OSB to provide that seal. One sealant bead should be placed close to the panel's edge (at the OSB).

The use of spray polyurethane foam at low temperatures is not advisable because spray foams rely on heat to generate a chemical reaction that expands the agents. Most manufacturers concur that ambient temperatures lower than $40^{\circ} \mathrm{F}$ are not conducive to expanding and curing the foam and are likely to result in an ineffective seal. Mastic products tend to have an even narrower recommended installation temperature range, $50^{\circ}-85^{\circ} \mathrm{F}$. Some OSB tapes; e.g., Advantech's zip system, can be installed in temperatures as low as $20^{\circ} \mathrm{F}$. These tested conditions, and the need to ensure the seal of the OSB for technical success, recommend that retrofits be timed with the seasons in cold climate zones and edge sealing products be selected appropriate for the temperature conditions at installation.

\footnotetext{
${ }^{7}$ www.wunderground.com/
} 


\section{Conclusions}

This project evaluated the effectiveness and affordability of integrating retrofit insulated panels into a re-siding project. A calculation of the improvement in energy use during February, normalized by utilities actually used divided by the HDDs in the period, is shown in Table 9. February was selected because monitoring data are available for that month for the base condition and the post-retrofit condition. Based on the normalization ratio, the energy use is calculated for a typical 1,200-HDD February period for the year before the retrofit (2013) and the year after the completed retrofit (2015). The heating energy savings associated with the gas use were measured at $21 \%$.

Table 9. Normalized Energy Savings for February

\begin{tabular}{l|c|c|c|c|c|c|c|c|c}
\hline & $\begin{array}{c}\text { Feb } \\
\text { HDD }\end{array}$ & $\begin{array}{c}\text { Gas Use } \\
\text { (Therms) }\end{array}$ & $\begin{array}{c}\text { Ratio } \\
\text { Therms/ } \\
\text { HDD }\end{array}$ & $\begin{array}{c}\text { Electricity } \\
\text { Use } \\
(\mathbf{k W h})\end{array}$ & $\begin{array}{c}\text { Ratio } \\
\mathbf{k W h} / \\
\text { HDD }\end{array}$ & $\begin{array}{c}\text { Use Normalized to } \\
\mathbf{1 , 2 0 0} \text { HDD }\end{array}$ & \multicolumn{2}{|c|}{$\begin{array}{c}\text { Energy Savings } \\
\text { from 2013 } \\
\text { Baseline }\end{array}$} \\
\hline & & & & & & Gas & Electricity & Gas & Electricity \\
\hline $\mathbf{2 0 1 3}$ & 1,038 & 930 & 0.90 & 896 & 0.86 & 1,076 & 1,036 & & \\
$\mathbf{2 0 1 5}$ & 1,433 & 1,008 & 0.70 & 1,036 & 0.72 & 844 & 868 & $21 \%$ & $16 \%$ \\
\hline
\end{tabular}

The energy savings results are about $10 \%$ lower than estimated through simulations for the installed energy-efficiency measures (based on the limited data available). The difference is attributed to higher average indoor temperatures post-retrofit and the observed opening of windows by the occupants to moderate indoor temperatures (due to a lack of accessible heating controls in each unit).

Cost is reported as the incremental cost for the energy-efficiency measures per square foot of the retrofitted wall or ceiling area rather than of the conditioned floor area. The added cost of the insulating effort provided by the retrofit panels was only slightly higher than the cost of the standard re-siding work - $\$ 7 / \mathrm{ft}^{2}$ versus $\$ 6.10$ - a difference of $15 \%$ over the targeted metric of the one-to-one ratio. The documented costs provide a reasonable basis for incorporating energyefficiency upgrades into façade improvement activities. The results support Building America goals of providing a reliable and economical energy conservation measure option for existing buildings and a pathway for market expansion by trades contractors and remodelers. 


\section{References}

Alfano, S. 2013. “Cost vs. Value Report 2013.” Remodeling Magazine, accessed October 2015: www.remodeling.hw.net/2013/costvsvalue/division/middle-atlantic.aspx.

Antretter, F., Karagiozis, A. TenWolde, and A. Holm. 2007. "Effects of Air Leakage of Residential Buildings in Mixed and Cold Climates." Presented at the Buildings X Conference,www.ornl.gov/sci/roofs+walls/staff/papers/142.pdf.

ASHRAE. 2015. Consumer Center FAQ. https://www.ashrae.org/resources--publications/freeresources/consumer-center-faq.

BASF. 2014. BASF Neopor® Expandable Polystyrene Beads 2200, F2200, 2300, F2300, 2400, F2400, 5300, F5300 and F5300 Plus. Wyandotte, MI: BASF Corporation, www.icces.org/Reports/pdf_files/ESR-2784.pdf.

Carll, C.G., and T.L. Highley. 1999. "Decay of Wood and Wood-Based Products above Ground." Buildings Journal of Testing and Evaluation, 27(2) 150-158, www.fpl.fs.fed.us/documnts/pdf1999/carl199a.pdf.

Census Bureau. 2011. Census Bureau, 2011. "How American Homes Vary By the Year They Were Built." Washington, D.C.: U.S. Census Bureau, www.census.gov/hhes/www/housing/housing_patterns/pdf/Housing\%20by\%20Year\%20Built.pd $\underline{f}$.

Certainteed. 2013. Installation Guide: Vinyl and Polymer Siding Installation. www.certainteed.com/resources/CTS205.pdf.

Diamond, R. A. Sanstad, T. Sanquist, and L. Lutzenhiser. 2010. "Understanding Household Retrofit Decision Making: Who, What, When, How, \& Why.” Berkeley, CA: Lawrence Berkeley National Laboratory, http://apps1.eere.energy.gov/buildings/publications/pdfs/building_america/ns/a19 laboratory pe rspective.pdf.

EPA. 2011. "Transitioning to Low-GWP Alternatives in Building/Construction Foams." Accessed October 26, 2015: www.epa.gov/ozone/downloads/EPA_HFC_ConstFoam.pdf.

Herk, A. 2012a. NYSERDA Deep Energy Retrofits: House 1 Report, Exterior Spray Foam Retrofit Strategy. IBACOS. http://www.nyserda.ny.gov/-/media/Files/EIBD/ResidentialBuildings/IBACOS-House-1-Report.pdf

Herk, A. 2012b. NYSERDA Deep Energy Retrofits: House 2 Report, Exterior Rigid Foam Retrofit Strategy. IBAQOS. http://www.nyserda.ny.gov/-/media/Files/EIBD/ResidentialBuildings/IBACOS-House-2-Report.pdf. 
Herk, A. 2013. NYSERDA Deep Energy Retrofits: House 3 Report, Exterior Rigid Foam Retrofit Strategy. IBACOS. http://www.nyserda.ny.gov/-/media/Files/EIBD/ResidentialBuildings/IBACOS-House-3-Report.pdf.

JCHS. 2013, p.2. The US Housing Stock Ready for Renewal Improving America's Housing 2013. Cambridge, MA: Joint Center for Housing Studies of Harvard University, www.jchs.harvard.edu/sites/jchs.harvard.edu/files/harvard_jchs_remodeling_report_2013.pdf.

McIlvaine, J., S. Saunders, E. Bordelon, S. Baden, L. Elam, and E. Martin. 2013. The Next Step Toward Widespread Residential Deep Energy Retrofits (Subcontract Report, NREL/SR-550057978). Golden, CO: National Renewable Energy Laboratory, www.nrel.gov/docs/fy13osti/57978.pdf?gathStatIcon=true.

Novikova A., F. Vieider, K. Neuhoff, and H. Amecke. 2011. "Drivers of Thermal Retrofit Decisions - A Survey of German Single- and Two-Family Houses." Climate Policy Initiative Berlin, http://climatepolicyinitiative.org/wp-content/uploads/2011/12/Drivers-of-ThermalRetrofit-Decisions-A-Survey.pdf.

SIPA. 2014. Retrofit Insulated Wall \& Roof Panel Installation Guide. www.sips.org.

TRUFAST. Guide to Attaching Sheathing, Furring, and/or Cladding through Continuous Foam Insulation to Wood Framing, Steel Framing, Concrete and CMU Substrates with TruFast SIP TP, SIP LD, and Tru-Grip Fasteners. www.trufast.com/links/pdf/TRU110910-21_CI_Evaluation_Report_2013-02-27.pdf

Wiehagen, J., and V. Kochkin. High-R Walls for Remodeling: Wall Cavity Moisture Monitoring (Subcontract Report, NREL/SR-5500-55205). Golden, CO: National Renewable Energy Laboratory, www.nrel.gov/docs/fy13osti/55205.pdf.

Wilson, A. 2010. "Avoiding the Global Warming Impact of Insulation." Green Building Advisor. Accessed October 26, 2015:

www.greenbuildingadvisor.com/blogs/dept/energy-solutions/avoiding-global-warming-impactinsulation. 


\section{Appendix A: Solutions Center}

\section{Scope Tab}

When major renovations are undertaken to modernize or add curb appeal to existing buildings, an opportunity arises to significantly increase energy efficiency by improving the thermal performance of the building enclosure. Retrofit insulated panels (or retrofit panels or nail base panels) present a straightforward way to add continuous insulation and air sealing to older homes as part of a comprehensive energy retrofit plan or as an energy-efficiency measure when replacing siding. The composite panels consist of rigid insulating foam laminated to a single sheet of OSB structural sheathing (Figure A-1).

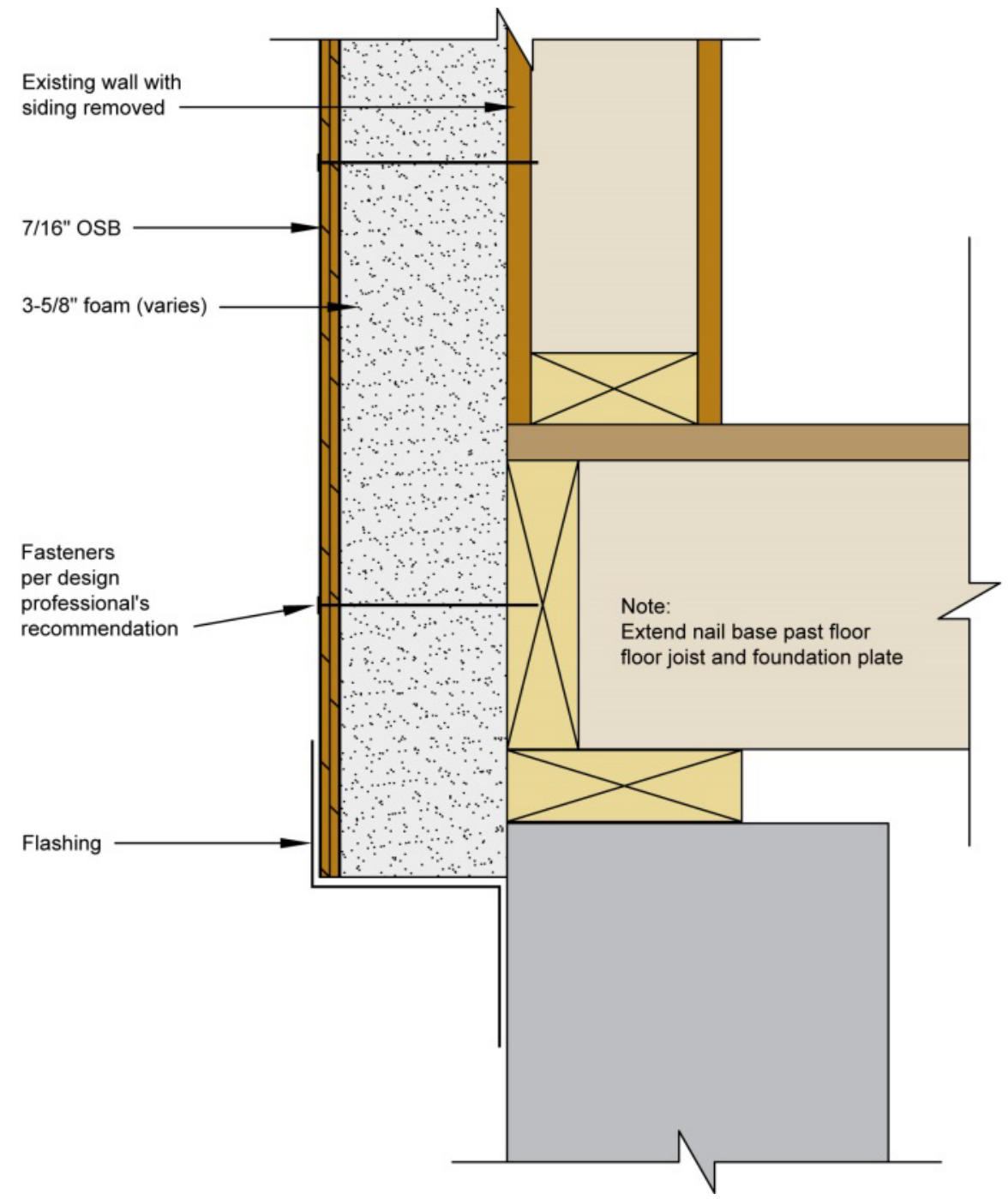

Figure A-1. Typical retrofit panel installation starting from bottom of building

Panels are cut to fit onsite and attached over the existing wall and/or roof sheathing to provide added insulation without disturbing the inside of the home. New cladding is then installed over 
the retrofit insulated panels. The OSB face serves as the fastening surface, or nailing base, for cladding. The cost is about equal to the cost of a re-siding project, which becomes more affordable when the two - adding curb appeal and adding the comfort provided by energy efficiency - are combined in the same project.

Retrofit insulated panels are available in a variety of thicknesses and sizes. Thicker panels have a higher R-value or thermal resistance. The R-value of a retrofit panel per inch varies with the type of foam insulation that is used in the panel. Table A-1 covers the R-values for EPS retrofit panels, which are the most common insulation type. Panel R-values vary by density of the EPS or other type of foam that makes up the retrofit panel.

Table A-1. EPS Retrofit Insulated Panel R-Values

\begin{tabular}{c|c|c}
\hline $\begin{array}{c}\text { Total Panel } \\
\text { Thickness }\end{array}$ & $\begin{array}{c}\text { R-Value Per ASTM } \\
\text { C 578, }{ }^{\mathbf{a}} \text { EPS } \\
\text { Type VIII }\end{array}$ & $\begin{array}{c}\text { R-Value Per ASTM } \\
\text { C 578, }{ }^{\text {a Neopor }} \\
\text { (Graphite Enhanced) }\end{array}$ \\
\hline $\mathbf{2}$ in. & 6.4 & 7.5 \\
\hline $\mathbf{4}$ in. & 14 & 16.5 \\
\hline $\mathbf{6}$ in. & 21.6 & 25.5 \\
\hline $\mathbf{7 - 3}$. in. & 28.3 & 33.3 \\
\hline $\mathbf{9 - 3}$ in. & 35.9 & 42.3 \\
\hline $\mathbf{1 1 - 3}$ in. & 43.5 & 51.3 \\
\hline
\end{tabular}

${ }^{a}$ Stated R-value includes EPS at thickness plus 7/16-in. OSB R-value from ASHRAE Fundamentals.

${ }^{\mathrm{b}}$ Stated R-value includes graphite-enhanced EPS, per manufacturer's International Conservation Code-Evaluation Services report at thickness, plus 7/16-in. OSB R-value from ASHRAE Fundamentals, rounded.

\section{Description Tab}

For the 44\% of the nation's housing stock built before 1970 (Census Bureau 2011), tackling the replacement of failing external components presents the ideal opportunity to improve a home's comfort and energy efficiency along with its curb appeal. The challenges are to maximize the insulating value of the material(s) applied to the walls of these homes and minimize associated costs such that the incremental costs of the insulation and air sealing can be compared favorably to the cost of the siding, window, or door replacement. In a test case, retrofit insulated panels were installed for $115 \%$ of the cost of the new siding installation. This brought the total cost of the building façade and energy-efficiency upgrade to $\$ 13.10$ per shell square foot or finished surface area, which was slightly more than twice the cost of "siding only." 
Table A-2. Cost of 4-in. and 6-in. Retrofit Panel Installation per Shell Square Foot

\begin{tabular}{c|c}
\hline Task & $\begin{array}{c}\text { Cost/Shell Square Foot } \\
\text { (\$) }\end{array}$ \\
\hline Aerogel Insulation & 0.04 \\
2-in. Nail Base Panels & \\
4-in. Nail Base Panels & \\
\hline 6-in. Nail Base Panels ${ }^{\mathbf{a}}$ & 3.12 \\
Panel Labor $^{\text {Equipment }}$ & 2.19 \\
Design-Panels $^{\text {Accessories }}$ & 0.33 \\
Windows $^{\mathbf{b}}$ & 0.27 \\
Extensions $^{\mathbf{b}}$ & 0.58 \\
\hline Total Cost-Retrofit Panels & 0.14 \\
\hline
\end{tabular}

${ }^{a}$ Average cost per square foot for all nail base panels

${ }^{\mathrm{b}}$ Polyvinyl chloride, boiler exhaust pipe, and sprinkler pipe through-wall extensions to accommodate panel thickness.

Table A-3. Cost of Re-Siding per Square Foot of Installed Surface

\begin{tabular}{c|c}
\hline Task & $\begin{array}{c}\text { Cost } / \mathbf{f t}^{\mathbf{2}} \\
\mathbf{( \$ )}\end{array}$ \\
\hline Siding and Accessories, Vinyl & 2.40 \\
Siding Labor & 2.51 \\
Equipment & 0.17 \\
Demo Existing Siding & 0.75 \\
Design & 0.27 \\
\hline Total Cost-Retrofit Panels & $\mathbf{6 . 1 0}$ \\
\hline
\end{tabular}

\section{Ensuring Success Tab}

The building air sealing success of the retrofit insulated panel method lies chiefly in the retrofit insulated panel's characteristic of being a single component that provides the subsurface requirements for both insulation and siding: R-value and a nailing base. The component can provide an air seal with perimeter spray foam or mastic adhesive applied to OSB edges while the panel is being set into place.

All the known industry best practices can be used to address finishes to the wall after the panels are installed. Moisture barrier and drainage plane are provided by a weather-resistive barrier. Flashing at wall penetrations, planar interruptions (such as the rear porch roof brackets), and terminations follow established methods for sheathed light frame walls that are well known in the industry. 
The size and location of the continuous mastic or spray polyurethane foam beads shown in the Installation Guide's details (SIPA 2015) are extremely important, as is the temperature of the panels and the air at installation time. One of the lessons learned from a project that took place from Dec. 2013 through March 2014, over a winter in which 6,655 HDDs were recorded, is that the air seal that can be provided by these panels relies on the panel's OSB surface providing that seal. One sealant bead should be placed close to the panel's edge (at the OSB).

\section{Climate-Specific Factors/Details Tab}

The use of spray polyurethane foam at low temperatures is not advisable because spray foams rely on heat to generate a chemical reaction that expands the agents. Most manufacturers concur that ambient temperatures lower than $40^{\circ} \mathrm{F}$ are not conducive to expanding and curing the foam and likely result in an ineffective seal. Mastic products tend to have an even narrower recommended installation temperature range of $50^{\circ}-85^{\circ} \mathrm{F}$. Some of the OSB tapes; e.g., SIGA's Wigluv 60 and Advantech's zip system, can be installed in temperatures as low as $14^{\circ} \mathrm{F}$ or $20^{\circ} \mathrm{F}$, respectively. These tested conditions, and the need to ensure the seal of the OSB, recommend that retrofits be timed with the seasons in cold climate zones and edge sealing products be selected wisely.

\section{Training Tab}

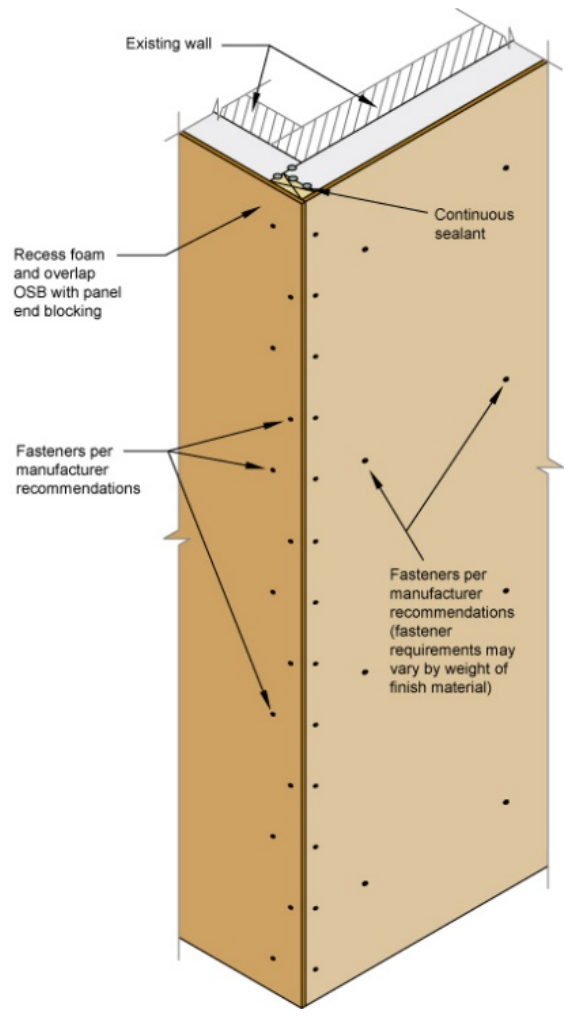

Figure A-2. Do start the retrofit panel layout at an outside corner of the building

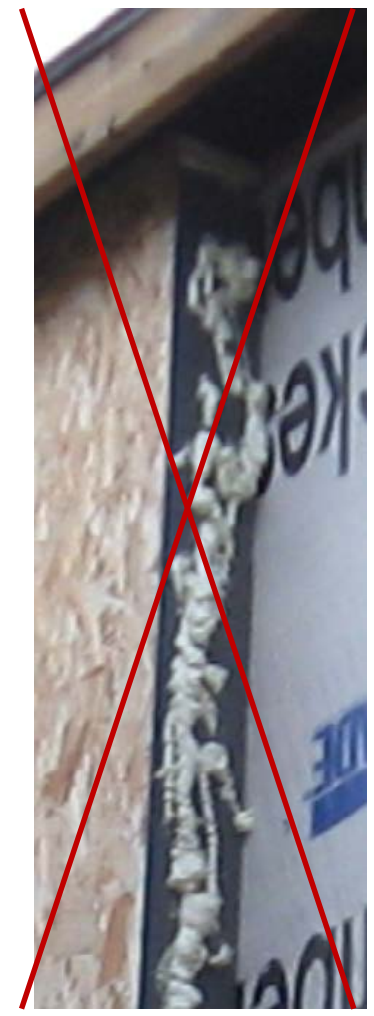

Figure A-3. Do not apply spray foam to panel edges as sealant in freezing weather conditions

Images from SIPA (2015) 


\section{Architectural CAD Files Tab}

Any of the figures from the Installation Guide may be used here.

\section{Compliance Tab}

Retrofit insulated panels are primarily a building rehabilitation product as opposed to a new construction component. The panels have also been used over new masonry walls to provide exterior insulation and a siding attachment surface. No building permit was required for either the retrofit insulated panel or the siding installation at the Albany, New York, site. The authors recommend that either the siding manufacturer or the retrofit panel manufacturer be consulted about the installation instructions for the cladding product for attachment to OSB sheathing (framing members are typically not accessible).

\section{More Info Tab}

\section{Case Studies}

Structural Insulated Panel Assoc., 2013. Cold Climate Retrofit

http://www.sips.org/downloads/cold_climate handout_v4.pdf.

\section{Bibliography}

American Chemistry Council, Guidance on Best Practices for the Installation of Spray Polyurethane Foam. Guidance for Residential Homes and Commercial Buildings. http://polyurethane.americanchemistry.com/Spray-Foam-Coalition/Guidance-on-Best-Practicesfor-the-Installation-of-Spray-Polyurethane-Foam.pdf.

Antretter, F., Karagiozis, A., et al. Buildings X Conference, 2007. The Effects of Air Leakage of Residential Buildings in Mixed and Cold Climates. www.ornl.gov/sci/roofs+walls/staff/papers/142.pdf.

Baker P. and Makepeace C. 2012. Adapting PERSIST for the Prevention of Water Accumulation in Residential Wood Frame Construction. http://web.ornl.gov/sci/buildings/2012/2001\%20B8\%20papers/078 Password Removed.pdf.

Berman, M., et al. for Alliance for Residential Building Innovation for U.S. Department of Energy, NREL 2012. Strategy Guideline: Mitigation of Retrofit Risk Factors. www.nrel.gov/docs/fy13osti/56669.pdf.

Building Science Corp. for NREL. 2005. Installing Windows with Foam Sheathing on a WoodFrame Wall. www.nrel.gov/docs/fy05osti/37583.pdf.

Census Bureau, 2011. Working Paper 2011-18: How American Homes Vary By the Year They Were Built. www.census.gov/hhes/www/housing/housing_patterns/pdf/Housing $\% 20$ by $\% 20$ Year\%20Built.pdf 
Certainteed. Vinyl and Polymer Siding Installation. Instructions indicate $3 / 4$ " nail embedment at 16-24" for horizontal vinyl lap siding. www.certainteed.com/resources/CTS205.pdf.

Cold Climate Housing Research Center. 2009. REMOTE a Manual. http://cchrc.org/docs/best_practices/REMOTE_Manual.pdf.

Diamond, R. et al. Understanding Household Retrofit Decision Making: Who, What, When, How, \& Why.

http://apps1.eere.energy.gov/buildings/publications/pdfs/building_america/ns/a19 laboratory_pe rspective.pdf.

FastenMaster. Technical Evaluation Report: Use of FastenMaster HeadLoc Fasteners to Attach Cladding and/or Furring to Wood Framing Through Foam Sheathing. www.fastenmaster.com/details/product/headlok-heavy-duty-flathead-fastener.html.

Foam Sheathing Coalition, 2013. Technical Evaluation Report-Attachment of Windows with Integral Flanges Through Foam Plastic Insulating Sheathing to Wood.

http://fsc.americanchemistry.com/Construction-Details/TER-No-1304-01.pdf.

Foam Sheathing Coalition, 2012. Technical Evaluation Report-Construction Details for the Use of Foam Plastic Insulating Sheathing (FPIS) in Light-Frame Construction. http://fsc.americanchemistry.com/Construction-Details/Construction-Details.pdf.

Foam Sheathing Coalition. Exterior Walls. http://fsc.americanchemistry.com/Exterior-Walls.

Hendron, R., et al. for NREL, 2010. Building America House Simulation Protocols. www.nrel.gov/docs/fy11osti/49246.pdf.

Herk, A. 2012. NYSERDA Deep Energy Retrofits: House 1 Report, Exterior Spray Foam Retrofit Strategy. IBAQOS. http://www.nyserda.ny.gov/-/media/Files/EIBD/ResidentialBuildings/IBACOS-House-1-Report.pdf

Herk, A. 2012. NYSERDA Deep Energy Retrofits: House 2 Report, Exterior Rigid Foam Retrofit Strategy. IBAQOS. http://www.nyserda.ny.gov/-/media/Files/EIBD/ResidentialBuildings/IBACOS-House-2-Report.pdf.

Herk, A. 2013. NYSERDA Deep Energy Retrofits: House 3 Report, Exterior Rigid Foam Retrofit Strategy. IBAQOS. http://www.nyserda.ny.gov/-/media/Files/EIBD/ResidentialBuildings/IBACOS-House-3-Report.pdf.

Herzog, B. and Yeh, B., Phd, P.E. for the Engineered Wood Association. Nail Withdrawal and Pull Through Strength of Structural Use Panels. www.apawood.org/pdfs/unmanaged/WCTENailWithdrawal.pdf.

Holliday, M. 2012. The High Cost of Deep Energy Retrofits: A Pilot Project Generates Cost Data on Deep-Energy Retrofits of Four Buildings in Utica New York. www.greenbuildingadvisor.com/blogs/dept/musings/high-cost-deep-energy-retrofits. 
Joint Center for Housing Studies of Harvard University, 2013, p.2. The US Housing Stock Ready for Renewal Improving America's Housing 2013.

www.jchs.harvard.edu/sites/jchs.harvard.edu/files/harvard_jchs_remodeling_report_2013.pdf.

McIlvaine, J. et al. for Building America Partnership for Improved Residential Construction, NREL. 2013. The Next Step Toward Widespread Residential Deep Energy Retrofits.

Novikova A. et al., Climate Policy Initative Berlin. 2011. Drivers of Thermal Retrofit Decisions - A Survey of German Single- and Two-Family Houses CPI Report.

http:/climatepolicyinitiative.org/wp-content/uploads/2011/12/Drivers-of-Thermal-RetrofitDecisions-A-Survey.pdf.

Remodeling magazine and the National Assoc. of Realtors, 2013. Cost vs. Value Report 2013. www.remodeling.hw.net/2013/costvsvalue/division/middle-atlantic.aspx.

Structural Insulated Panel Association, 2013. Retrofit Insulated Wall and Roof Panel Installation Guide. www.sips.org/downloads/SIPA_retrofit_guide 10-3-13.pdf.

TruFast. Guide to Attaching Sheathing, Furring, and/or Cladding through Continuous Foam Insulation to Wood Framing, Steel Framing, Concrete and CMU Substrates with TruFast SIP TP, SIP LD, and Tru-Grip Fasteners.

www.trufast.com/links/pdf/TRU110910-21_CI_Evaluation_Report_2013-02-27.pdf.

U.S. Environmental Protection Agency. Transitioning to low GWP Alternatives in Building/Construction Foam. www.epa.gov/ozone/downloads/EPA_HFC_ConstFoam.pdf.

Whelton, Michael G., et al. Proceedings for the $20^{\text {th }}$ Annual Conference of the International Group for Lean Construction, 2012. Cost Performance of Energy Efficiency Measures in Residential Retrofit Projects.

www.iglc20.sdsu.edu/papers/wp-content/uploads/2012/07/94\%20P\%20168.pdf. 


\section{Appendix B: Indoor Conditions: Temperature and Relative Humidity}
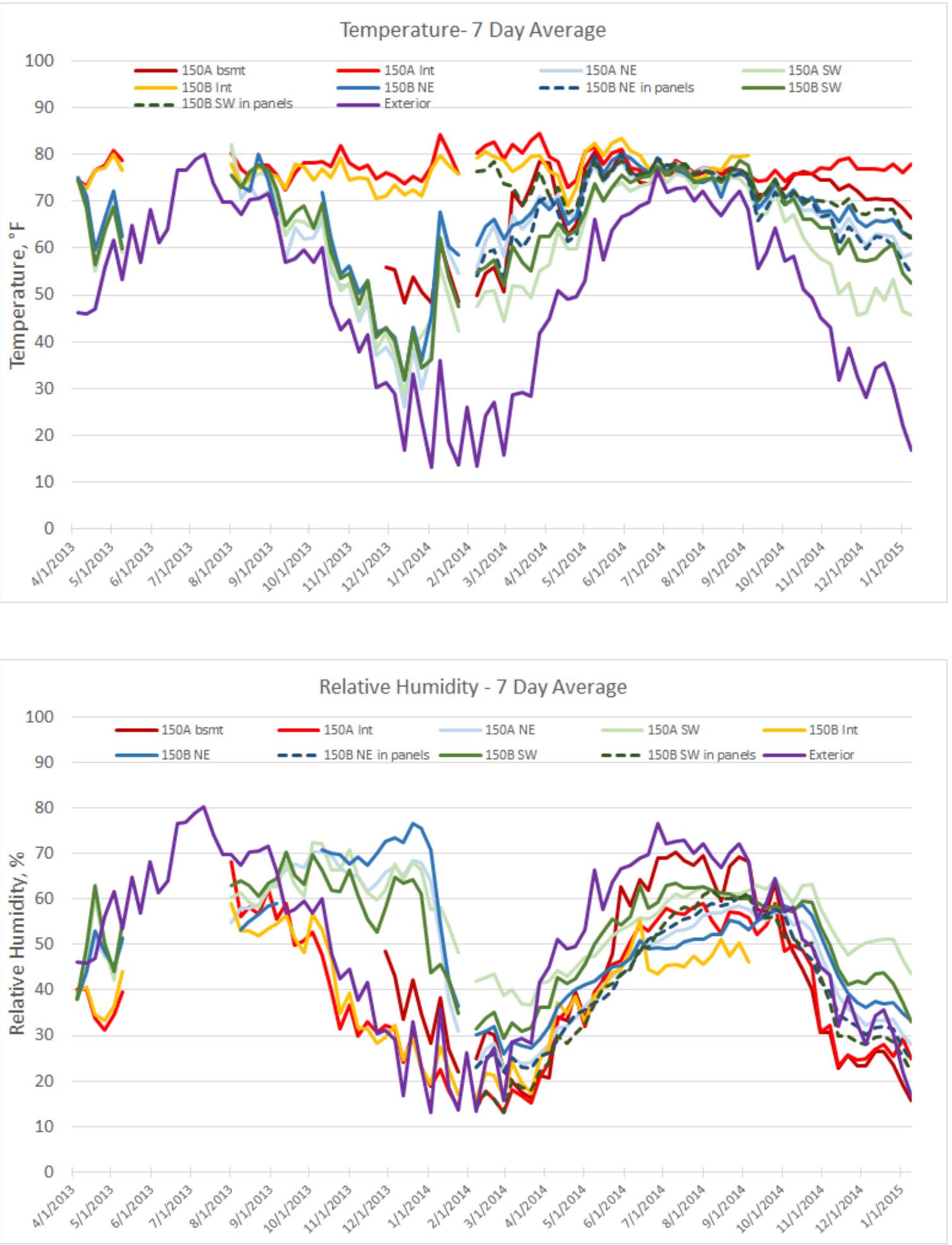

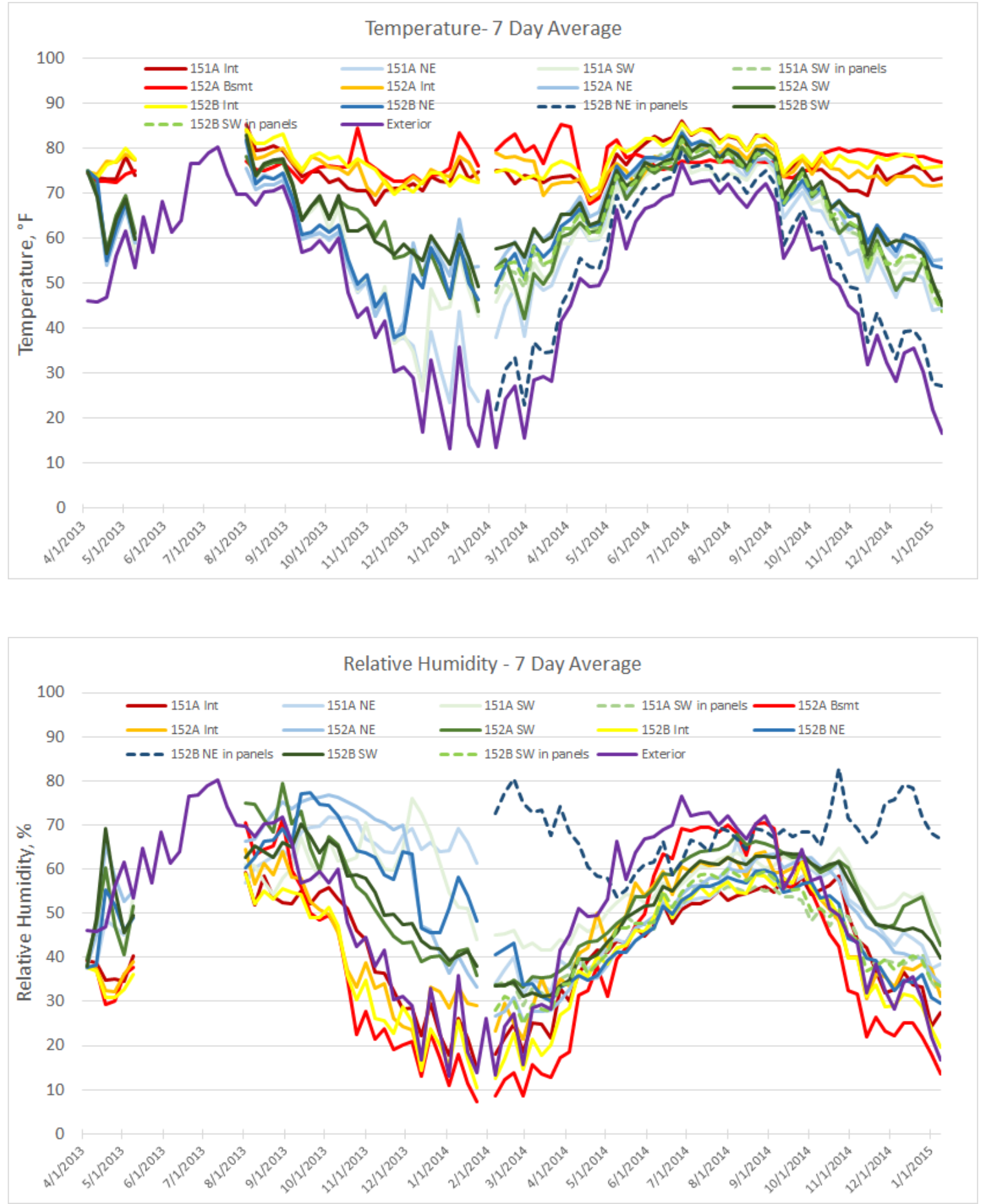

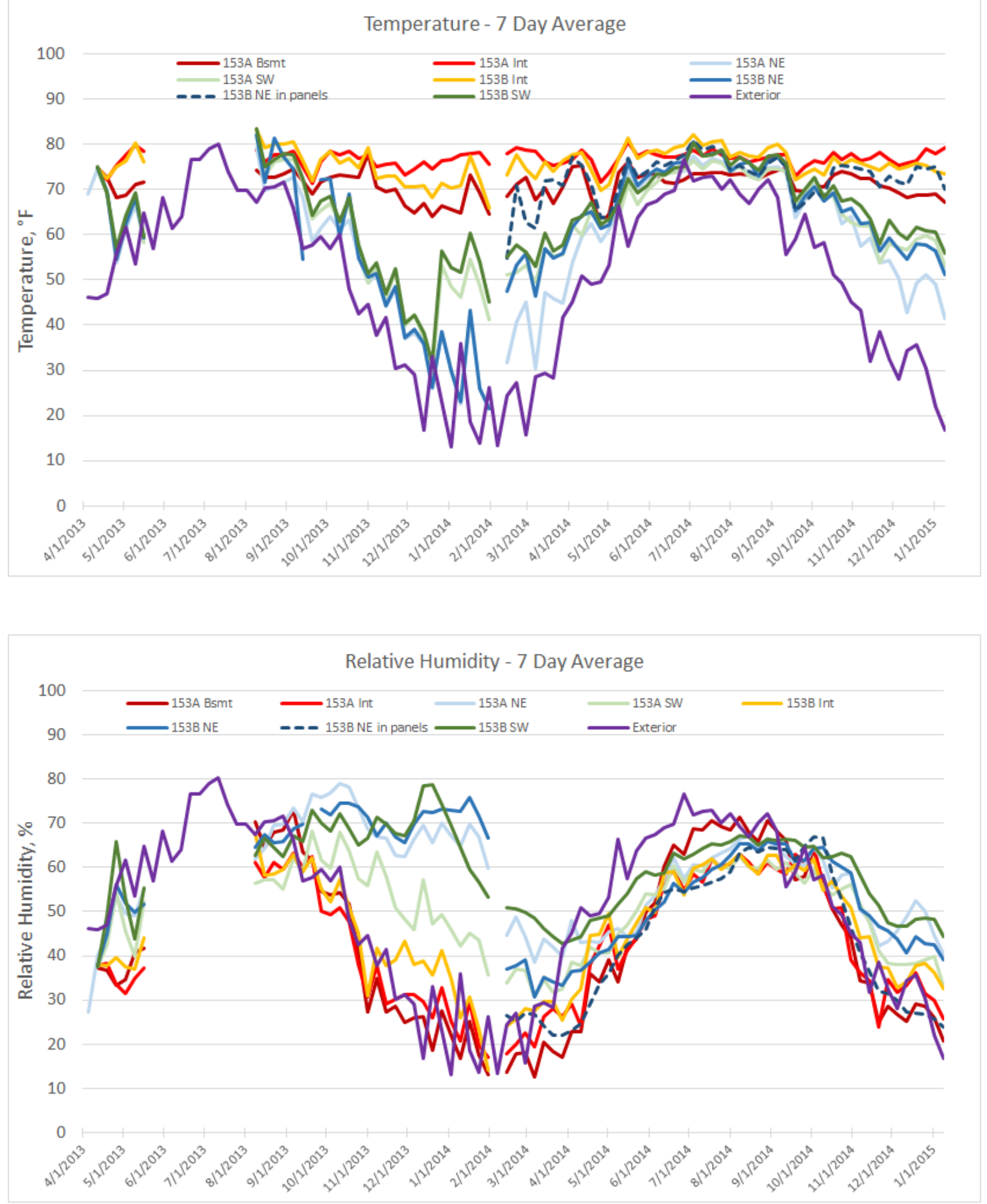


\section{Appendix C: Indoor Conditions: Daily Temperature Fluctuation}

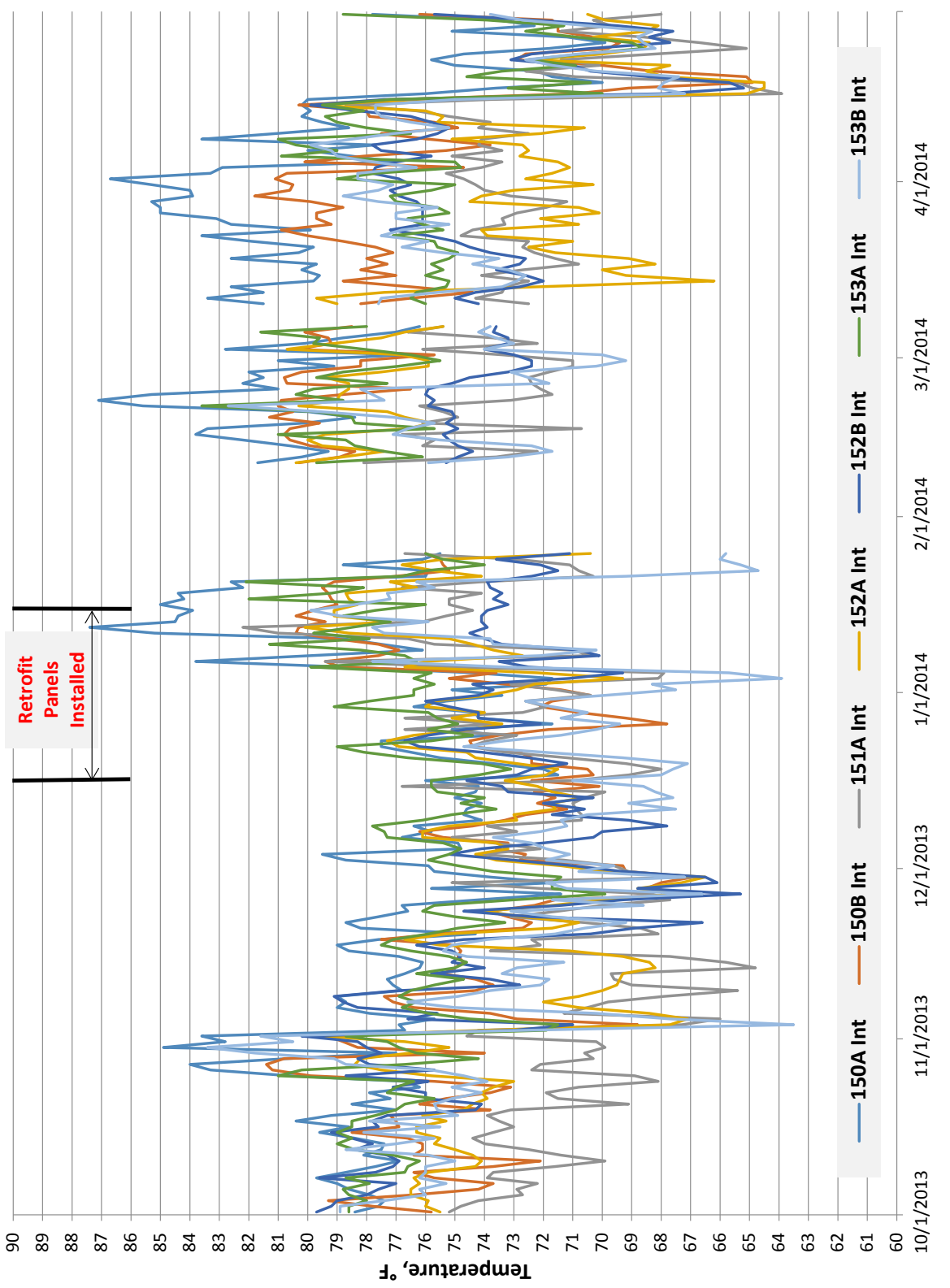


